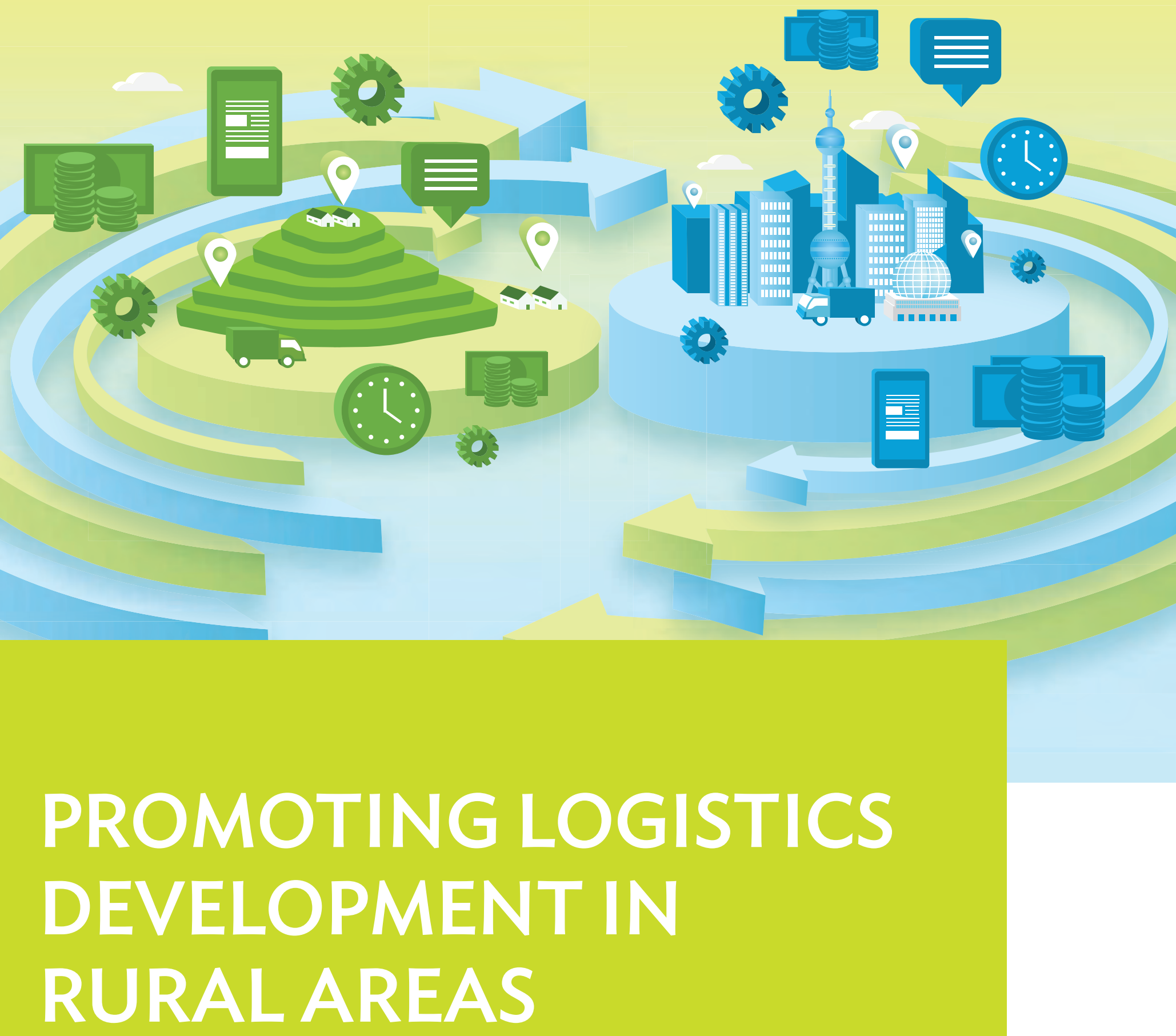




\section{PROMOTING LOGISTICS DEVELOPMENT IN RURAL AREAS}


(C) 2017 Asian Development Bank

6 ADB Avenue, Mandaluyong City, 1550 Metro Manila, Philippines

Tel +632632 4444; Fax +6326362444

www.adb.org

Some rights reserved. Published in 2017

ISBN 978-92-9257-991-3 (print), 978-92-9257-992-0 (electronic)

Publication Stock No. TCS 179027

DOI: http://dx.doi.org/10.22617/TCS179027

The views expressed in this publication are those of the authors and do not necessarily reflect the views and policies of the Asian Development Bank (ADB) or its Board of Governors or the governments they represent.

ADB does not guarantee the accuracy of the data included in this publication and accepts no responsibility for any consequence of their use. The mention of specific companies or products of manufacturers does not imply that they are endorsed or recommended by ADB in preference to others of a similar nature that are not mentioned.

By making any designation of or reference to a particular territory or geographic area, or by using the term "country" in this document, ADB does not intend to make any judgments as to the legal or other status of any territory or area.

This work is available under the Creative Commons Attribution 3.0 IGO license (CC BY 3.0 IGO)

https://creativecommons.org/licenses/by/3.0/igo/. By using the content of this publication, you agree to be bound by the terms of this license. For attribution, translations, adaptations, and permissions, please read the provisions and terms of use at https://www.adb.org/terms-use\#openaccess

This CC license does not apply to non-ADB copyright materials in this publication. If the material is attributed to another source, please contact the copyright owner or publisher of that source for permission to reproduce it. $A D B$ cannot be held liable for any claims that arise as a result of your use of the material.

Please contact pubsmarketing@adb.org if you have questions or comments with respect to content, or if you wish to obtain copyright permission for your intended use that does not fall within these terms, or for permission to use the ADB logo.

Notes:

In this publication, “\$” refers to US dollars.

Corrigenda to ADB publications may be found at http://www.adb.org/publications/corrigenda 


\section{CONTENTS}

Foreword vi

Acknowledgments vii

Abbreviations viii

Executive Summary ix

The Scope of This Study ix

The Critical Issues regarding Rural Logistics ix

Overview of Recommendations $\quad x$

| Overview of Rural Logistics in the People's Republic of China 1

A. Special Characteristics of Rural Logistics in the People's Republic of China 1

B. A New Phase of Economic Development in the People's Republic of China 3

C. The Industrial Structure 3

D. Challenges in Rural Development 4

E. The Key to Rural and Urban Development 6

F. Logistics Performance in the People's Republic of China $\quad 7$

II Rural-Logistics Institutional Framework and Policy Development in the People's Republic of China 9

A. Agricultural-Modernization and Rural-Transformation Policies 9

$\begin{array}{ll}\text { B. The Framework for Rural Logistics Supervision } & 10\end{array}$

C. The Ministry of Agriculture and Affiliated Departments 11

D. The Ministry of Commerce and Affiliated Departments 11

E. China Co-op and Affiliated Departments 12

F. Measures by the Ministry of Transport and State Post Bureau to Promote Rural Logistics 13

G. The "Green Channel Policy" 13

H. An Exploration of New Operating Models 14

$\begin{array}{ll}\text { I. Freight Transport Networks } & 14\end{array}$

$\begin{array}{ll}\text { J. Merging Rural Service Centers } & 15\end{array}$

K. Current Government Policies on Rural Logistics Development 15

L. Weaknesses in Policy Implementation 21 
III Information Technology and Rural Logistics 25

A. E-commerce Trends in Rural Areas $\quad 25$

B. The Rapid Development of Parcel Express Companies 27

C. Players and Platforms Entering Rural E-Commerce and Logistics 28

D. Drivers and Bottlenecks of Rural E-commerce 29

E. The Impact of E-Commerce on the Agricultural Logistics Industry 32

F. The Development and Application of Big Data Technologies 33

G. The Development and Application of Cloud Computing Technology 33

H. Applications of Modern Information Technologies to Farming and Logistics 36

I. Outlook 36

IV International Experiences in Rural Logistics Development 37

A. The World Bank's Logistics Performance Index 38

B. Comparing Integrated Logistics Parks 39

C. The United States Experience $\quad 40$

D. The German Experience 46

E. The Japanese Experience $\quad 48$

V Recommendations for Improving Rural Logistics 51

A. Public Sector Recommendations

B. Private Sector Recommendations $\quad 55$

$\begin{array}{lr}\text { References } & 59\end{array}$ 


\section{FIGURES, TABLES, AND BOXES}

\section{Figures}

1 Income per Capita in the People's Republic of China, 1979-2015 4

2 Logistics Costs as a Percentage of Gross Domestic Product in the People's Republic of China and the United States, 2000-2013 7

3 Rural E-Commerce Transaction Value, 2014-2016 26

4 Comparison of Rural and Urban Online Consumer Growth Year-on-Year, 2010-2015 26

5 The Logistics Information System $\quad 34$

6 A Typical Farm-Produce Value Chain in the United States 40

7 Business Logistics Costs in the United States as a Percentage of Nominal Gross Domestic Product, 2006-2015 42

\section{Tables}

1 Major Policies and Measures by Government Agencies regarding the Seven Key Areas of Rural Logistics

2 Profiles of the People's Republic of China, the United States, Germany, and Japan, 2014

3 Country Rankings in the World Bank's Logistics Performance Index, 2014

4 A Comparison of the Planning, Design, Financing, Construction, and Operation of Integrated Logistics Parks in the United States, Germany, and Japan

5 Recommendations for Improving Rural Logistics in the People's Republic of China

\section{Boxes}

1 The Agricultural Supply Chains in the People's Republic of China 2

2 The Case of the Fresh Tomato Value Chain from Shandong to Beijing 23

3 The Lingjiatang Wholesale Market's Fresh-Food Delivery Service 30 


\section{FOREWORD}

ogistics plays an important role in agricultural production and supply-chain management, ultimately enhancing food safety and quality. Improvements in rural logistics help farmers to harvest and market crops more efficiently; and by facilitating communication, they serve to expand the markets for agricultural products. Developing rural logistics can result in effective and efficient distribution channels between urban and rural areas; improve the quality and value of agricultural products; and provide low-cost, highquality consumer goods to the countryside.

While recognizing the rapidly changing rural scene currently, the rural logistics system in the People's Republic of China (PRC) is still weak, the organization structure inadequate, the distribution of goods impeded, and the quality of services poor. The PRC's rural logistics system is yet to meet the requirements for agricultural modernization. Promoting the development of rural logistics will facilitate structural adjustment and the industrialization of agriculture, providing important support for its modernization. It will also narrow the gap between urban and rural areas, thereby enhancing the PRC's goal for social harmony and stability.

The PRC wishes to establish efficient logistics systems in rural areas to enable unimpeded distribution channels for agricultural inputs and products and manufactured consumer goods to and from rural areas, and promote the development of the agriculture sector. In 2009, the PRC's State Council introduced the Logistics Industry Restructuring and Revitalization Plan, which identified the need to improve the value chains for agricultural produce and the distribution of consumer goods by developing better logistics systems in rural areas. Following this Plan, this publication recommends four necessary policies for promoting logistics development in rural areas: (i) enhance government support, (ii) strengthen rural logistics infrastructure, (iii) increase the informatization of rural logistics systems, and (iv) cultivate strong rural logistics enterprises.

We hope this publication will be of interest to policy makers in the agriculture and logistics sectors, practitioners, and researchers in the PRC, and to other developing countries that face similar challenges regarding rural logistics.

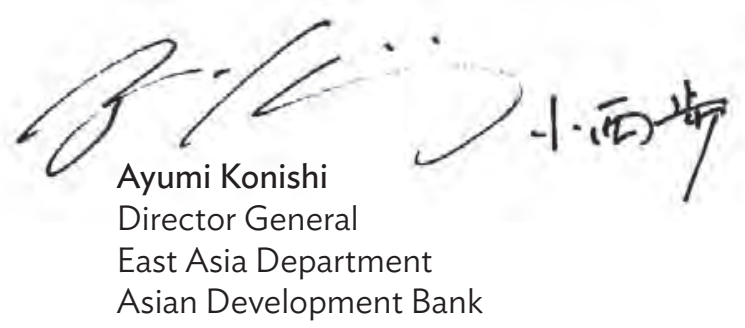




\title{
ACKNOWLEDGMENTS
}

\author{
- his publication is based on the findings of the technical assistance for Strategy and \\ Transport Policy Study on Promoting Logistics Development in Rural Areas, a project \\ of the Asian Development Bank. Jurgen Sluijter led the implementation of the \\ technical assistance, and Robert Guild provided overall guidance and supervision.
}

The team that produced the technical assistance report included national consultants Megan Gao, Harold Liu, Xiaoping Tan, and Jianguo Yang, and international consultants Kevin Chen and Andy Sze. Their work consisted of a combination of desk research and field visits. National experts and stakeholders in the People's Republic of China also contributed, by means of consultations and interviews.

This publication was reviewed by Chen Chen, Gloria Gerilla-Teknomo, Oleg Samukhin, and Philip Striednig. 


\title{
ABBREVIATIONS
}

\author{
ADB Asian Development Bank \\ CNY yuan (currency of the People's Republic of China) \\ EU European Union \\ GDP gross domestic product \\ HACCP Hazard Analysis Critical Control Point \\ IT information technology \\ LPI Logistics Performance Index (World Bank) \\ NDRC National Development and Reform Commission
}




\section{EXECUTIVE SUMMARY}

\section{The Scope of This Study}

The concept of rural logistics encompasses transport, distribution, storage, material handling, and the packaging of goods in rural areas, as well as the flow of information and funds in support of rural production and consumption. Rural logistics encompasses more than just the outbound flow of agricultural products from rural areas. It includes the movement of agricultural inputs and consumer products into rural areas, as well as the movement of light industrial goods produced in villages. Rural logistics also carries a regional connotation, as it focuses on logistics activities in administrative regions at or below the county level, among them county-level cities, autonomous county-level administrative units, townships, and villages.

Rural logistics development is an important part of the modernization of the agriculture sector of the People's Republic of China (PRC), which is essential for enhancing the living standards of rural residents. It is also a critical step toward urban-rural integration and improvements in the quality of village life.

\section{The Critical Issues regarding Rural Logistics}

Under its economic development model, the Government of the People's Republic of China plays an important role in managing the economy. Many economic actors are state-owned enterprises. Consequently, government policies exert a much stronger influence on the economy in the PRC than in countries like Germany, Japan, and the United States.

The activities of many government agencies affect the development of rural logistics. The National Development and Reform Commission, the Ministry of Commerce, Ministry of Agriculture, Ministry of Transport, Ministry of Finance, Ministry of Public Security, the China Co-op, and the State Post Bureau are among major government agencies involved. However, these agencies will need to coordinate with each other to enhance the overall efficiency and effectiveness of their efforts.

The agriculture sector of the PRC is composed mainly of tiny farms; and the plots are not only small, but frequently noncontiguous. The level of supply-chain intermediation is very high, as products from small-scale farmers have to go through brokers in both the origin and destination wholesale markets just to build economical shipping lots. Small shipment sizes, along with low rural traffic density, means that rural transporters are unable to reap enough profits to grow.

Due to poor profit margins, violations of regulations (e.g., illegal overloading) are common among rural transport operators, creating a situation in which "bad carriers drive out good 
carriers." The resulting deterioration in operating standards limits the propagation of good operating practices.

Rural logistics flows consist of

(i) the highly seasonal and cyclical outbound flows of farm products,

(ii) inbound flows of agricultural inputs that are also seasonal and cyclical, but precede the outbound flows of farm products by weeks or months;

(iii) a steady inbound flow of consumer staples and durables; and

(iv) a steady outbound flow of light industrial goods.

Because the flows are nonsynchronous, and because the shipments differ in their weights, sizes, and in the nature of their cargoes, it can be very difficult to achieve fast vehicle turnaround times, high-load transports, and a reduction of empty backhauls. Temporary storage facilities, good cargo information platforms, and intelligent network management are key drivers in balancing the cargo flows.

There is a shortage of electronic payment systems in rural locations, so rural trade is still based on "cash and carry." Few modern trading channels such as online auctions can be found in rural areas, and farmers have difficulty accessing important information such as spot market prices and supply-and-demand forecasts.

These serious problems lead to high transportation costs, relentless competitive pressure, and the inability to scale up or to afford equipment. This leads to poor service quality and compromises safety and sustainability.

\section{Overview of Recommendations}

\section{A. Public Sector Recommendations}

\section{Enhance Government Support}

With the wide variety of institutions and stakeholders involved in rural logistics, special attention should be given to making policy formulation and implementation more effective, and this should involve authorities at the national, provincial, and local levels. Government policies concerning transportation, commerce, farm supply, and marketing need to be integrated. During implementation, a leading role should be given to local governments.

Funding from the national, provincial, and local governments is needed to support the upgrade of rural vehicles and equipment, the construction of a rural logistics publicinformation network, and the promotion of private sector involvement. The government should also expand investment channels, streamline loan application procedures, and help finance rural logistics enterprises to support their growth.

There should be improved standards and specifications for commodity circulation, information platforms, equipment and technology, and business operations related to 
agriculture. This would include temperature-recording devices and other instruments to support uninterrupted cold-chain transport and in-transit temperature-monitoring capabilities.

The relevant agencies within the Ministry of Transport, Ministry of Agriculture, the Ministry of Public Security, and the Ministry of Commerce, as well as China Co-op and various local government departments handling rural-logistics issues, should be encouraged to share information on logistics infrastructure, credit and trade practices, safety violations, and rural logistics-service supply and demand-as this will support rural logistics development.

The role of markets should be strengthened, with private enterprises as the main driver in creating logistics information platforms and mobile applications. The government should promote interconnectivity among logistics information platforms and enterprise information systems to effectively link various players in the supply chain.

\section{Strengthen Rural Logistics Infrastructure}

There should be improvements in the coordination of rural-logistics-infrastructure planning by the Ministry of Transport, Ministry of Commerce, China Co-op, and the State Post Bureau, especially with regard to infrastructure locations, resource sharing, and co-development. The central government should promote the unified planning of rural logistics in selected provinces, and prefectural or city-level rural logistics planning should be synchronized with provincial development planning.

The government and the private sector should cooperate in developing logistics parks with comprehensive functions pertaining to agricultural product circulation, processing, storage, transport, and distribution. They should strengthen the linkages between logistics park planning and other planning related to the development of the PRC's agricultural market system. They should also cooperate in the construction of supporting logistics parks (cargo hubs) with circulation, processing, storage, transport, and distribution functions. And they should strengthen the overall planning and construction of logistics parks (cargo hubs) and postal logistics distribution centers, with the aim of intensively integrating the logistics resources of the transport and postal sectors. Finally, they should strengthen the interconnectivity between existing logistics parks and agricultural production bases, agricultural product wholesale markets and distribution nodes, and agricultural input distribution centers, as well as postal distribution centers, in order to upgrade the effectiveness of rural logistics.

The central government and local authorities should work to integrate the rural logistics resources pertaining to transport, commerce, farm supply and marketing, and postal services; develop a rural logistics network based on three levels of nodes (county or district, township, and administrative village); and follow the model of "multiple functions in one node, with resource sharing." With rural logistics centers serving as a base, they should also collocate rural markets, agricultural product collection points, renewable resource recycling centers, and agricultural-input distribution centers. And they should expedite the construction of county-level rural logistics hubs and nodes to centralize the management of rural logistics supply and transport, and to improve the connections with the national trunk logistics networks. 


\section{B. Private Sector Recommendations}

\section{Increase the informatization of rural logistics systems}

At present, rural supermarkets are generally small and offer few product varieties. This sector is characterized by high fragmentation and low profits, a situation that further hinders their development and limits employment opportunities for the rural labor force.

The business model for small rural supermarkets must be revised to enable stable, long-term development. Due to the remote locations and low levels of informatization in rural areas, villagers lack the conveniences of urban life. Transforming small rural supermarkets into multifunctional commerce and distribution centers would enable them to provide a variety of services to rural residents, such as helping customers order tickets online or purchase goods from e-commerce websites.

Mobile communication technology could provide convenient links between rural supermarkets and villagers. For instance, supermarkets would be able to receive or ship parcels or small lots of cargo on a villager's behalf. With their upgraded capabilities, small rural supermarkets would not only enrich the daily lives of villagers and promote employment in rural areas, but also maximize the value they add, leading to higher profits and stable, long-term growth.

Smartphone apps could make it easier for local villagers to deliver parcels or small lots of cargo to other villagers - via farm shops or rural supermarkets. Increasing e-commerce initiatives and a crowdsourcing approach would speed up the delivery and lower the delivery cost for the receiver. Overall, logistics costs and services, as well as sustainability, would improve with this new approach, enabling substantial improvements in rural logistics services.

\section{Cultivate Strong Rural Logistics Enterprises}

Logistics knowledge is a critical element in creating an efficient and reliable rural logistics system. Field studies have revealed a strong need to strengthen the logistics competency of rural transport and logistics operators. Unless logistics performance is measured, there is no objective way of telling if the results are getting better or worse. The managers of logistics enterprises should thus be encouraged to use performance indicators.

Standards and specifications are essential for the efficient operation of a rural logistics system. In a sense, standards form a common language for the various parties along a supply chain. To establish effective logistics standards and specifications, the Ministry of Transportation should form a Standards and Specifications Committee. The work of this committee should encompass "software," as well as "hardware" areas-for example, business processing and equipment standards, to ensure that trading partners and logistics service providers achieve interoperability and to enable the visibility of goods moving through the supply chain.

The existing transport and logistics networks need to be rationalized to facilitate the movement of multiple types of cargo via multiple transport modes. For example, the bottoms of passenger buses should be used to ship small packages, and crowdsourcing techniques should be used to deploy registered villagers to pick up or deliver packages for other villagers.

The government should support private sector development of low-cost rural logistics terminals to consolidate shipments of agricultural products brought in by farmers, and to distribute consumer goods and nonlocally produced food to the villagers. These rural logistics centers could serve as nodes connecting village-level roads to county-level and regional roads. They could also facilitate the aggregation of farm products into batches large enough to transport cost-effectively. 


\title{
I. OVERVIEW OF RURAL LOGISTICS IN THE PEOPLE'S REPUBLIC OF CHINA
}

\begin{abstract}
- he concept of rural logistics encompasses transport, distribution, storage, material handling, and the packaging of goods in rural areas, as well as the flow of information and funds in support of rural production and consumption. Rural logistics encompasses more than just the outbound flow of agricultural products from rural areas. It includes the movement of agricultural inputs and consumer products into rural areas, as well as the movement of light industrial goods produced in villages.
\end{abstract}

In this publication, the rural logistics systems of the People's Republic of China (PRC) are analyzed and assessed for the purpose of recommending strategies and policies for improving rural-urban transport synergies. Best practices from different countries will also be presented to offer insights on development of policies that would assist the PRC's own rural development.

\section{A. Special Characteristics of Rural Logistics in the People's Republic of China}

Agriculture in the PRC is highly fragmented, with each rural household acting as a small-scale production unit. This is partly due to the transition from collective to private farming and the scarcity of fertile land. The whole supply chain-from the procurement of farm inputs to the planting, harvesting, and transport of the produce-is thus characterized by the participation of micro-operators and a low level of organizational efficiency. This fragmentation of agriculture, in turn, affects the scale, degree of fragmentation, and productivity of rural logistics operators.

Overall, the large differences between urban and rural logistics are due to the large differences between urban and rural culture; living standards; and, especially, production methods.

Agricultural production is generally concentrated in certain seasons, but rural residents demand consumer staples on a daily basis year-round. Different agricultural products have different planting, growth, and harvesting times, and they require different farm inputs. The outbound flow of farm products rarely synchronizes with the inbound flow of farm inputs and consumer goods, so adequate storage and warehousing are essential for balancing the inbound and outbound flows, and for smoothing out the seasonal agricultural-production peaks and valleys.

The large variety of agricultural products and production methods creates diversity in rural logistics. Agriculture encompasses the raising of crops, forestry, livestock production, and aquaculture - all of which vary widely in the amount of land they require and the difficulty of their operations. Each type of agriculture calls for different types of logistics services, and incurs different logistics costs. The fact that the PRC is a major agricultural producer with 


\section{Box 1: The Agricultural Supply Chains in the People's Republic of China}

Agricultural supply chains can be seen as pipelines for the efficient and effective flow of products, information, and funds. Indeed, the trend has been toward a tighter integration of supply chains linking producers and stakeholders, and a greater concentration of farms, food processors, and wholesalers. From the management perspective, however, agricultural supply chains are inherently more complex, more chaotic, and much harder to control than the supply chains for most manufactured products. For example, the supply chain for perishable farm produce is highly influenced by natural elements (seasons; rainfall; drought; temperatures; and fungal, viral, and pest infestation).

The special characteristics of the People's Republic of China's agricultural supply chains include the following:

(i) They are "push" type supply chains, with limited responsiveness, flexibility, and agility. For example, fruit trees typically start to bear fruit several years after planting. Once the planting has been completed, it is very hard to adjust to changes in demand. Also, even for short-cycle crops such as leafy vegetables, the actual amount supplied in the short run is not determined by consumer's "pull," but by elements such as rain, weather, insect infestation, and plant diseases.

(ii) They are highly seasonal and cyclical. The cultivation of crops is highly seasonal, causing supply peaks at harvest times that can exceed demand by a wide margin. Further, high prices spurred by high demand often lure farmers into overproduction. Wide seasonal swings and boom-and-bust cycles have ruined many farms.

(iii) Farming tends to be labor-intensive (except for grain, soybean, and corn production on large integrated farms), so small farms can focus on carefully targeted niches (e.g., organic heirloom tomatoes) in order to compete successfully with larger farms.

(iv) Farms have only a limited ability to scale. The best growing areas for various farm products are determined by the climate, soil, and water supply. Fertile land is scarce; and it is getting scarcer because urbanization and industrialization frequently remove the best land from farming. Labor intensity also limits the scalability of farming. The low scalability of agricultural supply chains means that one cannot make up for a large, sudden loss of a food staple with production from other locales. It also means that an increase in demand or an interruption in supply can quickly drive up the price of fresh produce.

(v) Agricultural production is characterized by uncertainty and low robustness. Farming is heavily impacted by the natural elements, which are beyond a farmer's control. Drought, flood, wind, diseases, and insect infestation can wipe out entire crops.

(vi) Demand risk is high, as is the risk of price volatility. Consumer tastes for farm products can be fickle, leading to sudden changes in demand. And even a small change in demand can lead to large swings in product pricing. Moreover, the consolidation of retail outlets and institutional food-service companies have shifted pricing power to large buyers.

(vii) There is a strong consumer demand for higher food quality (i.e., fresher, tastier, more nutritious, and preferably organic), and for higher food safety.

(viii) The logistics costs (as a percentage of the sales price) are high. Product perishability and the consumer preference for freshness lead to high transport, inventory (i.e., storage, spoilage, loss of shelf life), and logistics-management costs, especially when the product must be packed and chilled, transported in refrigerated vehicles, and then placed in cold storage facilities upon delivery.

Source: Asian Development Bank. 
wide variations among its regional economies further adds to the diversity of rural logistics. Box 1 describes the characteristics of agricultural supply chains in the PRC in more detail.

High empty-haulage rates and low vehicle-capacity utilization are common in rural areas. Postharvest product losses are often high due to insufficient facilities for cold storage, packaging, processing, and preservation. Better facilities would be more effective in protecting the freshness and safety of farm products, and in extending their availability and market reach.

\section{B. A New Phase of Economic Development in the People's Republic of China}

The PRC's gross domestic product (GDP) has been growing consistently and rapidly since 1982, exceeding CNY68 trillion in 2015. Since then, however, the growth rate has begun to slow down due to a profound change in the economy. Specifically, the PRC's economy has started transitioning from a rapid-growth phase to a medium-to-high growth phase. This new phase of economic development is assumed to be more stable, with an improved and higher value-added economic structure. Further, the economic drivers are becoming more diversified and consumer-oriented. The modernization of PRC's industrial sector is also playing a major role in this economic transformation.

\section{The Industrial Structure}

The PRC's industrial structure has adjusted well to the massive changes in the economy since the government introduced its "reform and opening up" policies in the late 1970s. "The economy's primary sector (agriculture and raw materials) decreased from 30\% of GDP in the early days of the reform to $8.9 \%$ in 2015 . The secondary sector (manufacturing) now hovers around $41 \%$ of GDP; and the tertiary sector (services) exceeded the secondary sector for the first time in 2013, when its share of GDP reached $46.1 \%$. The PRC's service industry has entered a stage of rapid development, reaching 48.2\% of GDP in 2014 and surpassing 50\% in 2015. This indicates a shift from an economy driven by heavy industries to a higher-valueadded economy.

The service industries will be the key to promoting economic restructuring and to accelerating the transformation of the PRC's economic growth model. With the upgrading of the industrial structure and the deepening of the country's economic restructuring, the share of the service industry in the GDP will increase further.

This rapid development of the tertiary sector will generate a strong increase in consumption. The PRC's service industries-especially modern industries, such as those involving e-commerce, transport, and warehousing-have developed very fast, thereby promoting further consumption and improving consumer product quality.

As an important part of national consumption, rural consumption plays a significant role in the national and rural economies. It not only provides a solid foundation for expanding domestic demand and for stimulating the sustained growth of the national economy, it is

\footnotetext{
1 "Reform and opening up" refers to the program of economic reforms, termed "socialism with Chinese characteristics," that was initiated by Deng Xiaoping in December 1978.
} 
also an important factor in promoting trade and reducing the disparities in income and living standards between urban and rural areas.

\section{Challenges in Rural Development}

Although the per capita income growth rate in rural areas exceeded the rate for urban areas during 2010-2015, rural incomes still lag behind urban incomes, and earning a decent living is still difficult for most Chinese farmers. Figure 1 shows that the net per capita income of rural residents was only about $34 \%$ of the per capita disposable income of urban residents.

Figure 1: Income per Capita in the People's Republic of China, 1979-2015

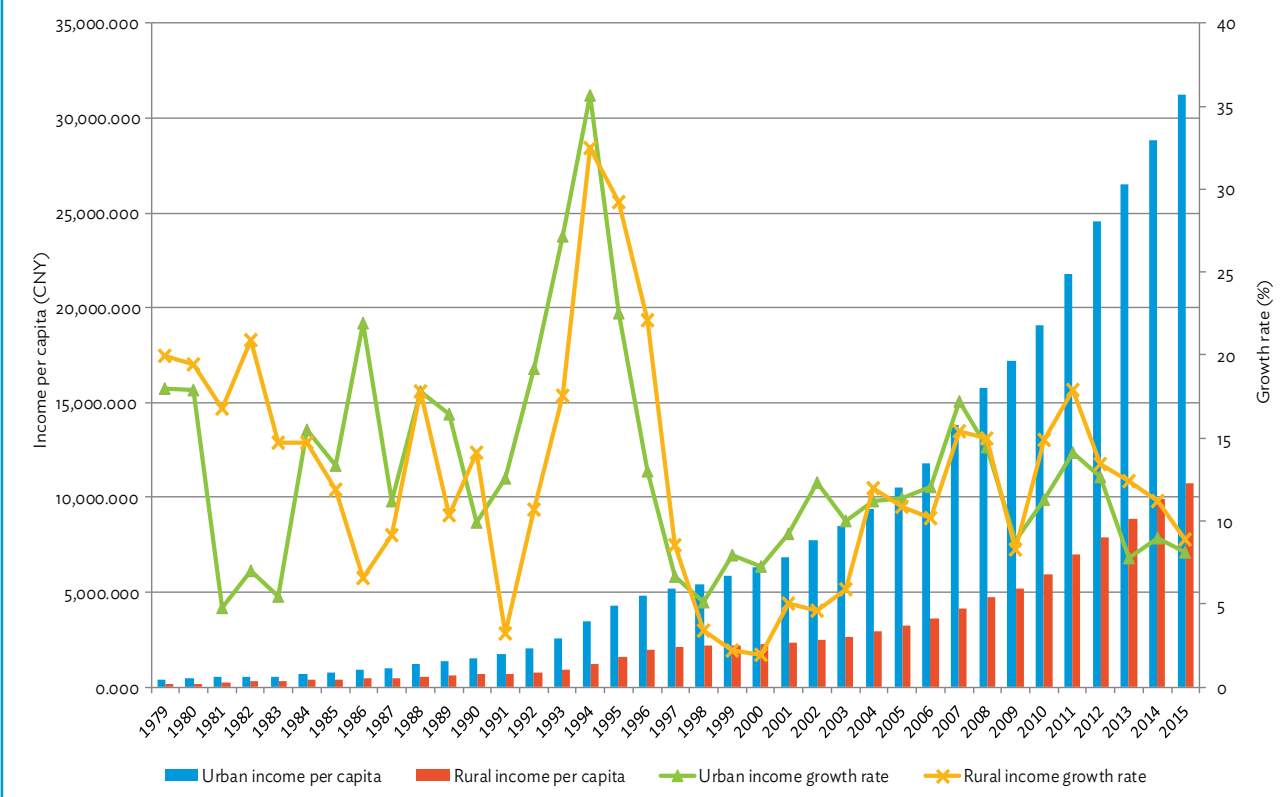

Sources: Government of the People's Republic of China, National Bureau of Statistics; International Monetary Fund.

There are 14 areas in a total of 680 counties in the PRC that are considered to have special socioeconomic difficulties. Tens of millions of people in rural areas are still facing problems such as unsafe drinking water and inaccessible roads, and some farmers still have no electricity. Many rural socioeconomic indicators are significantly low compared with those for urban areas, such as the rural compulsory education expenditure per student, per capita healthcare insurance expenditure, the average number of health technical personnel per thousand residents, subsistence allowance standards, cooperative medical subsidy standards, and social endowment insurance subsidy levels.

As part of the PRC's recent urban development strategy, the integration of urban and rural development aims to gradually equalize the quality of basic public services provided in urban and rural areas. The National Planning of New-Type Urbanization (2014-2020), issued by the Central Committee of the Communist Party of China and the State Council in March 2014, clearly mandates the promotion of fair exchanges of urban and rural areas, a balanced 
allocation of public resources, and rural-urban integration. This document specifically states the following objectives: (i) to integrate urban and rural planning, infrastructure, and public services; (ii) accelerate the coverage by public services in rural areas; (iii) improve the agricultural product circulation system; (iv) nurture modern commerce and new business models; and (v) to develop a low-cost, fast, and efficient distribution system.

However, due to the limitations of the dual rural-urban economic structure, rural areas are still not well-developed, and rural consumer markets are still not fully penetrated. There has been an increase in farmers' incomes, and this has resulted in a surge in rural consumption. Due to the vast differences in the local cultures and tastes of rural residents, however, there are substantial differences in the products they desire, so rural demand shows varied preferences. There is thus a need to develop a rural logistics infrastructure that not only unleashes rural consumption potential, but satisfies the varied demands of rural consumers.

Many agricultural areas shifted to industrial development as the economy grew. Following the acceleration of urbanization, rural residents and industries have started to congregate in small towns, with spatial distribution experiencing major structural changes. The increasing population in the new small towns has increased the demand for rural logistics services, offering fresh opportunities for rural logistics development. At the same time, due to continuous improvements in the allocative efficiency of urban and rural production factors, rural consumption is increasing, and is requiring more diverse and responsive rural logistics services.

\section{Dietary Changes}

Rapid urbanization in the PRC has been accompanied by rising incomes and a burgeoning middle class, resulting in a rapid shift in dietary patterns from a grain-based diet to a diet that is more protein-rich (meat and dairy) and diversified (fruits and vegetables). Annual per capita grain consumption declined from 235 kilograms in 1983 to 128 kilograms in 2013. Indeed, the consumption of fruits, edible oils, meat, poultry, and seafood has increased dramatically, and there are marked differences in the foods consumed in both rural and urban areas compared with the past. In fact, the growth rates of several food categories (animal products, fruits, and cooking oil) have been higher in rural than in urban areas, indicating a gradual convergence of consumption patterns between the two. Migrants to the cities are consuming much more meat, and are starting to adopt the same consumption patterns as urban residents. The change in food demand will require a considerable shift in the production portfolio of crops and other agricultural outputs.

The PRC's agricultural system beyond the farm gate has traditionally been composed of many small traders, processors, and retailers, with relatively short supply chains. The most rapid development in wholesale markets happened in the 1990s. More recently, wholesale markets have been established in every major town and city in the PRC.

\section{Modern Retail Chains}

With its rapid economic growth, increasing urbanization, and accelerated integration into the world market, the PRC has seen a surge in the number of supermarkets and large agricultural food companies. Among the top 47 retail chains selling food, sales totaled $\$ 13$ billion in 2001 and grew to a total of $\$ 117$ billion in 2011. This represents a compound annual growth rate of $27 \%$, almost three times faster than the country's GDP growth rate. The PRC has more than 3,600 agricultural wholesale markets; in 2010 these markets had a total trading value of more than CNY1.5 trillion, and the value of more than $20 \%$ of the trades exceeded CNY100 million. 
Agricultural products in the PRC are being increasingly shipped from production areas to cities over very long distances, facilitated by the country's expanding highway and road network. The recent trend toward a greater concentration of agricultural inputs and food distribution, the increasing role of information and logistic technologies, the growing importance of food safety and quality, and other technical requirements have all resulted in dramatic changes in Chinese agri-food systems. These systems have become more organized, with more linkages from the producer to the consumer, and with an increasingly dominant role being played by highly concentrated and specialized wholesalers, agro-industrial firms, and retailers.

The most notable change is that the procurement systems of modern retail chains are very different from those of traditional stores. First, modern retail chains increasingly require contracts with their suppliers. Such contracts allow supermarkets to control the safety and quality of procured products, ensure the desired supply volumes, and reduce price uncertainty. Second, numerous and costly criteria for supplier accreditation are on the rise among modern retail chains. The increased demand for technical certification (such as HACCP, ISO 9000, or HACCP-based farm quality assurance) means that the participation of producers is becoming contingent on their access to facilities that are adequately equipped for sorting, grading, packing, storing, and transporting. Third, modern retail chains are increasingly using regional and global sourcing networks to consolidate their procurement systems. Large retailers are moving away from local sourcing, with supermarkets preferring to rely on large traders with regional and global supply networks that can produce large volumes and various varieties at the required times, even when it comes to fresh produce. Fourth, there has been a significant shift in power away from agri-food processors and toward food retailers due to tougher contract negotiations and enforcement. Chain stores tend to reject deliveries of imperfect merchandise far more frequently than do produce wholesalers and brokers.

Several retailers such as Wumart, Tesco, and Carrefour have adopted a preferred supplier scheme, under which a supplier will be taken out of consideration if it cannot meet their volume and quality requirements. This means that processors and traders along the supply chain have had to adjust their behavior. Moreover, consumer food choices have also become increasingly influenced by supermarkets in the PRC.

\section{E. The Key to Rural and Urban Development}

The development of rural logistics is essential for equalizing the basic public services provided in urban and rural areas. However, the incompleteness of the rural road network was the key reason rural logistics was never included in previous government programs aimed at achieving this equalization. But as the result of a massive expansion in the rural road network recently completed by the government (Chapter 2 , section F), rural logistics will henceforth be included in such programs, especially given its importance in promoting unified ruralurban markets. This shift will have a profound impact on logistics development, calling for new thinking, innovative approaches, and ambitious reforms.

The PRC has a long way to go before meeting the requirements of agricultural modernization, but the development of rural logistics will facilitate structural adjustments and the industrialization of agriculture, thus providing an important support for the modernization of the agriculture sector. The development of rural logistics will also deeply impact the incomes, work opportunities, and daily lives of rural residents, as well as the relationship between urban residents and farmers. At present, however, many rural areas are still beset by the "hard to sell, expensive to buy" phenomenon: farmers experience difficulties in selling their products, and then pay too much for their daily necessities and household goods, further widening the urban-rural gap. 
Promoting the development of rural logistics can create effective and efficient distribution channels between urban and rural areas; improve the quality and value of agricultural products; and provide low-cost, high-quality consumer goods to the countryside. This will narrow the gap between urban and rural areas, thereby enhancing social harmony and stability in the PRC.

\section{F. Logistics Performance in the People's Republic of China}

Rural logistics deals with the part of an overall logistics system that starts and/or ends in rural areas. The weak foundation of the rural logistics system in the PRC, as well as its extensive length, large number of intermediation links, and wide geographic coverage, exerts a large negative impact on the logistics costs to the whole society.

The lack of coordination among government agencies with regard to policy formulation and implementation has led to an underutilization of resources, insufficient integration, and low efficiency. Strengthening coordination, and optimizing resource allocation and integration, would propel rural logistics development and, in doing so, would also contribute in a major way to a reduction of logistics costs.

In the past 2 decades, the PRC has made tremendous progress in its transport infrastructure development, yet its logistics costs have long remained at 18\% of the GDP - twice as high as in most developed countries (e.g., Germany, Japan, the United Kingdom, and the United States) (see Figure 2). Even in India, whose transport infrastructure is substantially less developed than the PRC's, logistics costs are lower, at 15\% of GDP.

Figure 2: Logistics Costs as a Percentage of Gross Domestic Product in the People's Republic of China and the United States, 2000-2013

Logistics

Cost as $\%$ of GDP

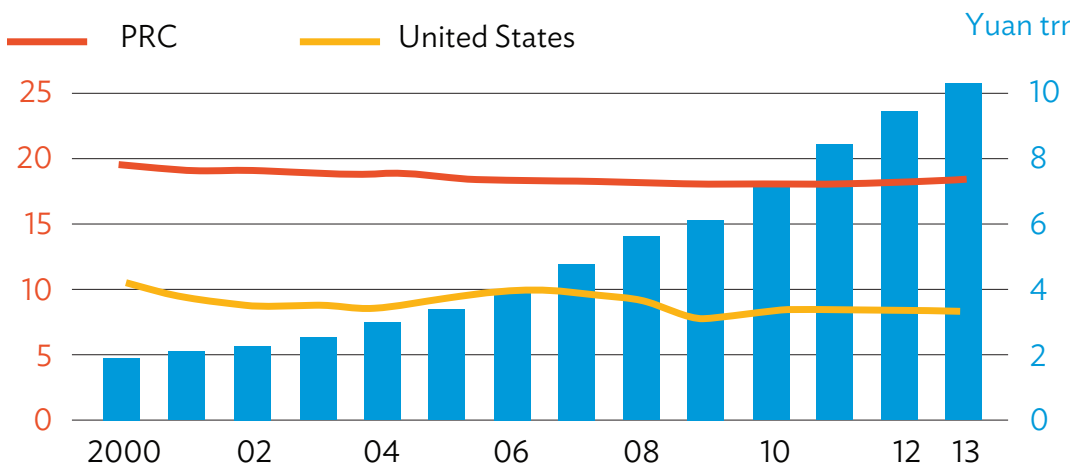

GDP = gross domestic product, PRC = People's Republic of China.

Note: In 2013, logistics costs as a percentage of GDP was less than half of the PRC's.

Sources: Government of the People's Republic of China. 2000 through 2013.

China Logistics Yearbook. Beijing; Council of Supply Chain Management Professionals. 2000 through 2013. State of Logistics Report. Lombard, IL, United States. 
Due to the special characteristics of rural logistics, the costs for the PRC's agricultural products are relatively high. This not only contributes to food price inflation for consumers, but also depresses the incomes of farmers in rural areas and worsens their living standards.

As the PRC's rural-to-urban migration continues, and as the income gap between rural and urban areas escalates, the creation of high-performing rural logistics systems is becoming a major development priority for the country. It is urgently needed to (i) support the modernization of agricultural supply chains, (ii) improve food safety, (iii) increase rural incomes, (iv) enhance the living standards of rural residents, and (v) protect the environment. 


\section{RURAL-LOGISTICS}

INSTITUTIONAL FRAMEWORK AND POLICY DEVELOPMENT IN THE PEOPLE'S REPUBLIC OF CHINA

\section{A. Agricultural-Modernization and Rural-Transformation Policies}

Since the founding of the PRC in 1949, the Government of the People's Republic of China has implemented a series of agricultural-modernization policies based on the specific status of agricultural development during various periods. In 2012, the 18th National Congress of the Communist Party of China proposed the Chinese-style "Four Modernizations": industrialization, information technology (IT) application, urbanization, and agricultural modernization. The National Congress also called for (i) a clarification of the relationship among the Four Modernizations, (ii) an in-depth integration of IT application and industrialization, (iii) a benign interaction between industrialization and urbanization, and (iv) coordination between urbanization and agricultural modernization.

Due to the rapid progress of industrialization, IT application, and urbanization, there is an urgent need for agricultural modernization to speed up, so as to stay in sync. The strategy based on the Four Modernizations spells out new guidelines for the smooth progress of agricultural modernization, and emphasizes the importance and urgency of this process.

The "three rurals" refer to "agriculture, rural areas, and farmers." And the "three rural issues" generally refer to "agricultural development, rural stability, and increased farmers' incomes." As the PRC is a major agricultural country, the three rural issues are tied to the quality of life, economic development, and social stability of the country.

The "No. 1 Central Document" is the first document issued by the Central Committee of the Communist Party of China ${ }^{2}$ at the beginning of each year. It is a programmatic and directive document that spells out the work to be done that year. From 2004 to 2015, the No. 1 Central documents focused on the three rurals and emphasized the "top-priority" status of the three rural issues during the PRC's socialist modernization period. The No. 1 Central documents of 2014 and 2015 designated agricultural modernization as the rural issue that had to be addressed first.

The 2014 document directed the government to work resolutely to remove the problems of institutional bureaucracy, support the fundamental role of agriculture, and accelerate agricultural modernization. In 2015, the document directed the government to conduct its reforms according to the rule of law and to accelerate agricultural modernization.

In fact, agricultural modernization has become the mainstream approach to resolving the three rural issues. It not only involves new tasks and goals regarding agricultural production techniques, but also entails new requirements for rural logistics services. Specifically, rural logistics services must respond to changes in production and consumption patterns and improve their timeliness and reliability. Rural logistics development must include

Central Committee of the Communist Party of China. 2004-2017. No. 1 Central Document. Beijing. 
strengthening the basic infrastructure and network design and layout to fulfill the basic requirements of agricultural modernization. In this regard, the No. 1 Central Document of 2015 outlined the following required actions:

(i) perfect the national network for agricultural product circulation, and clarify the requirements for developing rural logistics;

(ii) strengthen the storage-capacity and logistics infrastructure for important agricultural products;

(iii) speed up the construction of new 50-million-ton storage capacity grain warehouses;

(iv) promptly establish central and local grain collection and storage mechanisms, with a clear division of responsibilities;

(v) further the construction of wholesale markets in agricultural production areas;

(vi) accelerate the construction of a cross-regional cold chain logistics system;3

(vii) continue to implement pilot agricultural wholesale markets as a public service;

(viii) promote collaboration among farm cooperatives, supermarkets, schools, enterprises, and residential communities; and

(ix) support the construction of agriculture e-commerce platforms.

In addition, the document prioritizes the elimination of unreasonable, arbitrary charges for the transport and marketing of agricultural products, and promotes e-commerce pilots in rural areas.

The 2017 No. 1 Central Document, in turn, puts an even larger emphasis on the development of rural e-commerce, as it is seen as a successful vehicle for poverty alleviation. The development of online trading platforms for agricultural products as well as of e-commerce service points in villages is further promoted to achieve a real integration of online and offline activities. The extension and perfection of uninterrupted cold chain logistics infrastructure to remote areas is given priority.

\section{B. The Framework for Rural Logistics Supervision}

The rural logistics network in the PRC is huge and complex. At present, the major administrative bodies involved in rural logistics include the National Development and Reform Commission (NDRC), the Ministry of Commerce, Ministry of Agriculture, Ministry of Transport, Ministry of Finance, China Co-op, and the State Post Bureau. Although there is no overall planning and coordinating agency assigned specifically to supervise rural logistics, diverse administrative bodies have done a lot of work within their spheres to advance rural logistics and to lay a solid foundation for future development in this area.

3 A "cold chain" is a temperature-controlled supply chain, for instance, with refrigerated production, storage, and shipping facilities. 
The main responsibilities of the NDRC and of the provincial development and reform commissions involve planning and coordination, guiding interagency collaboration, and supporting high-priority government tasks. Recently, the NDRC emphasized the importance of agricultural logistics, rural-urban logistics, and rural distribution in major national logistics planning and policy documents. It is also paying close attention to cold chain logistics, with the formulation of special plans and policies to

(i) strengthen the cold chain logistics infrastructure;

(ii) develop third-party cold chain logistics;

(iii) scale up cold chain transportation;

(iv) improve the cold chain logistics standardization system;

(v) facilitate cold-chain information technology development; and

(vi) develop advanced distribution methods, such as joint delivery.

Encouraged by these policies, the cold chain logistics industry has expanded rapidly, building more cold chain logistics consolidation and distribution centers across the country.

\section{The Ministry of Agriculture and Affiliated Departments}

To promote agricultural trade, the Ministry of Agriculture and its provincial and local departments focus on building wholesale agricultural markets, improving the connection between agricultural production and marketing, and on developing agricultural e-commerce. To contribute to the construction of an agricultural logistics network, the Ministry of Agriculture and affiliated departments are offering better guidance on wholesale-market operations standards, coordinating the promotion of a "shopping basket program," ${ }^{4}$ and exploring new storage systems for fresh farm produce. There is now an increasing number of wholesale agricultural markets in the PRC that offer a comprehensive range of goods, including specialized products.

To improve operations, the agriculture sector is developing a capacity for the direct supply and sale of agricultural products, promoting the integration of production and marketing, exploring agricultural e-commerce, and actively fostering better market circulation. By the end of 2014, 1,790 wholesale agricultural markets (with an annual turnover of more than CNY100 million), as well as special direct agricultural trading platforms, had been successfully launched in Beijing, Hebei, Heilongjiang, Jiangsu, and Tianjin.

\section{The Ministry of Commerce and Affiliated Departments}

In its effort to further develop commercial systems, the Ministry of Commerce and affiliated departments are focusing on building multifunctional commercial outlets in rural areasunder the projects Building Standardized Farm Shops in 50\% of Villages and 70\% of Towns

\footnotetext{
4 The "shopping basket program" is an effort by the Ministry of Agriculture to alleviate shortages of non-staple foods such as vegetables, meat, eggs, and dairy products. The program aims to improve the supplies of these foods by offering subsidies to farmers and building facilities to improve production, storage, and distribution.
} 
Nationwide and One Hundred Large Agricultural Product Wholesale Markets and One Hundred Large Agricultural Product Trade Enterprises.

At the same time, the Ministry of Commerce and affiliated departments are encouraging the development of rural e-commerce, and of more effective agricultural trade. The Building Standardized Farm Shops in 50\% of Villages and $70 \%$ of Towns Nationwide project aims to encourage chain stores and supermarkets in urban areas to set up farm shops in rural areas through pilot ventures. The farm shops are encouraged to engage in the wholesale and retail trade of agricultural equipment and commodities, and to provide farmers with comprehensive services by combining wholesale and retail operations.

The One Hundred Large Agricultural Product Wholesale Markets and One Hundred Large Agricultural Product Trade Enterprises project aims to

(i) upgrade 100 large wholesale markets for agricultural products,

(ii) foster 100 new agricultural enterprises,

(iii) build a modern agricultural trade network linked to international markets,

(iv) broaden the channels for agricultural trade,

(v) safeguard against risks in agricultural trade, and

(vi) promote sustained income growth for farmers.

From 2005 to 2010, the Building Standardized Farm Shops in 50\% of Villages and 70\% of Towns Nationwide project invested a total of CNY11.7 billion and built 250,000 rural supermarkets. These markets now distribute over $50 \%$ of the goods sold in rural areas. From 2006 to 2010, the One Hundred Large Agricultural Product Wholesale Markets and One Hundred Large Agricultural Product Trade Enterprises project progressed rapidly, resulting in the founding of 100 new large wholesale agricultural markets and 100 new large agricultural enterprises annually.

\section{E. China Co-op and Affiliated Departments}

China Co-op and affiliated departments combine the development of community-owned enterprises with the New Rural Modern Circulation Network project. This project aims to

(i) create a multifunctional rural supply and marketing network,

(ii) achieve bidirectional flows of goods, and

(iii) foster the growth of lead farm supply and marketing enterprises.

The project has been investing an average of CNY350 million annually and has supported more than 400 programs since 2006. As a result, a new modern-circulation network has been established in rural areas that integrates the modern management-services network for agricultural-production equipment, the purchase-and-sale network for agricultural byproducts, and the network for consumer product recycling. 
At the same time, subnational governments in the PRC have achieved good results by actively investing in the construction of such networks. For example, the government of Hubei Province approved 40 projects in 2015 and supported them with investments totaling CNY25 million. These actions stimulated private investments in the projects totaling more than CNY100 million.

\section{F. Measures by the Ministry of Transport and State Post Bureau to Promote Rural Logistics}

Transportation is the basic link and principal component of logistics. Therefore, the Ministry of Transport and the State Post Bureau possess inherent advantages as agencies for rural logistics development. The development of rural road networks, transport hubs, freight stations, postal enterprises, network nodes, transportation equipment, freight-forwarding enterprises, and other facilities are all part of the promotion of rural logistics. In terms of approaches, the Ministry of Transport and State Post Bureau emphasize the use the existing postal system, the integration of postal and cargo transportation networks, and the extensive use of freight-transport companies to provide logistics services in rural areas.

Rural road construction has been a priority of the Ministry of Transport and provincial transport departments, and they have achieved remarkable results in this domain. By the end of 2014, the length of rural roads (at the county, township, and village levels) reached 388 million kilometers, with $99.98 \%$ of the townships (i.e., towns) and $99.82 \%$ of the administrative villages now accessible by road. ${ }^{5}$ The increased coverage and improved safety of the PRC's rural roads have provided a solid foundation for the improved circulation of agricultural products and agricultural inputs, facilitating bidirectional logistics channels for inbound consumer goods, farm inputs, and outbound agricultural products. Hence, a road network that is safer and provides greater geographic coverage has translated into a better quality of rural logistics services.

\section{G. The "Green Channel Policy"}

The "green channel" for fresh agricultural products began as a major project in 1995 to benefit the lives of citizens, and later became a key policy initiative of the Ministry of Transport. Jointly with the NDRC, the Ministry of Transport developed the "List of Fresh Agricultural Product Varieties." This list specified more than 100 kinds of fresh agricultural products (including vegetables, fruit, live poultry, meat, eggs, and milk), with the purpose of identifying agricultural cargoes that should be exempted from highway tolls.

Vehicles fully loaded with fresh farm produce have been exempt from tolls on roads, bridges, and tunnels since December 2010. Although this policy has resulted in forgone toll revenues, which exceeded CNY10 billion in 2014, it has facilitated the delivery of fresh farm produce to urban areas, and has played an important role in lowering circulation costs, thereby boosting trade in fresh farm produce. In Hubei Province, for example, 4.33 million vehicles transported fresh farm produce through the green channels in 2014, with the tolls saved amounting to as much as CNY1.41 billion.

\footnotetext{
5 However, in certain regions, the quality of the roads is not necessarily up to par. In Inner Mongolia and Xinjiang, for example, the roads are sometimes dirt or gravel roads, and a fair number of the paved roads are too narrow and have low safety ratings.
} 


\section{H. An Exploration of New Operating Models}

The Ministry of Transport and State Post Bureau have been actively exploring new mechanisms for sharing complementary resources and for diversifying risks by promoting the development of "multifunctional" and "multipurpose" rural logistics networks. Co-building rural logistics networks would serve as a means of sharing resources between the Ministry of Transport and the State Post Bureau. This would mean integrating networks, expanding the services offered by existing outlets, and using facilities in a complementary manner. Usually, the party possessing the station or site takes the lead in implementation. In the city of Yichang (Hubei Province), for example, the local transport and postal service departments cooperated in expanding service areas and developing rural logistics, with the support of an integrated logistics information platform, postal outlets, and the rural transport network.

By the end of 2013, Yichang had completed the construction of a "1+3+11+190" rural-logisticsnode layout: 1 city-level logistics center, 3 logistics distribution centers, 11 comprehensive rural logistics stations, and 190 administrative-village logistics network outlets. This has given Yichang a "single stop" comprehensive rural logistics system with integrated functions encompassing general goods transport, passenger transport, agricultural product transport, small-parcel express, agricultural input distribution, and logistics-information dissemination.

Freight yard innovation involves adding new functions to those of traditional freight yardssuch as small-parcel transport, express delivery, and a delivery service for agricultural inputs-in order to stimulate regional rural logistics development. Typically, such practice involves building (or rebuilding) comprehensive regional logistics freight yards. For instance, Weihui Cargo Transport Company, in Weihui County (Henan Province), built a modern freight station using its original station as a base, and combined its freight forwarding, cargo consignment, and cargo information departments to pool its cargo, introduce better standards to the market, and streamline management. Meanwhile, some rural passenger stations that had failed to attract sufficient traffic were transformed into logistics nodes by the local government. Platforms were built as part of a three-level (county, township, and village) network, making the rural passenger transport network accessible to every village. The postal offices at the county and village levels, as well as various transport networks, are being integrated to serve all rural areas, facilitating rural "door-to-door" transportation services and promoting an efficient use of resources.

\section{Freight Transport Networks}

Connecting a rural logistics network effectively with the trunk transportation network is an important part of promoting rural logistics development. For instance, Suheng Logistics Co., Ltd., in Dali County (Shaanxi Province), contributed four vehicles to help launch special freight routes serving rural clients. The company divided Dali County into four independent distribution zones and set up subordinated logistics networks in each. It opened four freight routes with daily roundtrips covering 18 towns and more than 200 administrative villages throughout the county, connecting 264 logistics points into a unified network. Through this "fixed time, fixed place, and fixed route" service, 11,300 tons of agricultural inputs were delivered and more than 2,800 vehicle trips were made during 2015-2016, saving merchants and farmers more than CNY2.8 million in shipping costs. In Dali County, the rural freight delivery service covers $80 \%$ of the towns and $40 \%$ of the villages. 


\section{J. Merging Rural Service Centers}

Much efficiency could be gained by forming a strategic alliance including the Ministry of Transport, State Post Bureau, China Co-op, Ministry of Commerce, and their respective affiliated departments to share various resources used for delivering agricultural inputs, agricultural products, and consumer goods.

For instance, the Transportation Department of Shandong Province signed a "Strategic Cooperation Agreement between the Transportation Sector and Postal Sector in Shandong Province" with the provincial Post Bureau and the Shandong branch of the State Post Bureau. They jointly issued a work plan for establishing a "four-in-one" township traffic management office, which would combine the rural transportation and postal services with the farmproduct supply and marketing service. The transportation department of every county has built a rural transportation and logistics distribution center to support rural bazaars or a township enterprise confluence zone. In addition, new freight stations have been built, and existing ones expanded, and more agreements have been signed with village-level freight outlets. In this way, a three-level logistics network with a distinct hierarchical structure began to take shape, with logistics centers in counties and cities, freight yards and stations in townships, and freight outlets in villages.

\section{K. Current Government Policies on Rural Logistics Development}

\section{A Review of National-Level Rural Logistics Policies and Measures}

In its Plan for Restructuring and Revitalizing the Logistics Industry (2009), the State Council advanced three development policies for rural logistics: (i) expanding market demand, (ii) promoting logistics development in key fields, and (iii) creating rural logistics projects. ${ }^{6}$

In the document titled "Opinion on Policies and Measures for Promoting the Healthy Development of the Logistics Industry" (2011), the General Office of the State Council clearly prioritized the development of the agricultural logistics industry; an increase in policy support for that development; and an acceleration of the setting up of a convenient, efficient, safe, and smooth logistics system for agricultural products. Further, the document stressed the importance of (i) developing direct sales and distribution methods, such as "direct connections between farm and supermarket," "direct connections between farm and school," and "direct connections between farm and enterprise"; (ii) supporting the development of professional farm cooperative organizations; (iii) strengthening the construction of large produce-distribution centers in major producing regions; and (iv) encouraging large supermarket chains, schools, hotels, businesses, and other end users to establish stable, long-term relations with farmers' cooperatives and production bases. ${ }^{\text {? }}$

In the document titled "Opinion on Deepening the Reform of the Distribution System to Expedite the Development of the Distribution Industry" (2012), the State Council recommends strengthening the policies on rural logistics development in four main ways:

\footnotetext{
6 Government of the People's Republic of China, State Council. 2009. Plan for Restructuring and Revitalizing the Logistics Industry. No. 8. Beijing.

7 Government of the People's Republic of China, State Council, General Office. 2011. Opinion on Policies and Measures for Promoting the Healthy Development of Logistics Industry. No. 38. Beijing.
} 
(i) boosting the construction of modern circulation systems; (ii) actively working to devise innovative distribution methods; (iii) increasing the supply capacity of agricultural markets; and (iv) reducing the tax burden on the circulation industry, as well as the circulation costs. The document also exempts agricultural wholesale markets and farmer's markets from the township land-use tax and property taxes for a certain period, extends the policy of exempting vegetable distribution from the value-added tax, and exempts vehicles fully loaded with fresh agricultural goods from toll payments. ${ }^{8}$

The Medium- and Long-Term Development Plan for the Logistics Industry (2014-2020) advances a rural logistics development policy that is focused on strengthening logistics enterprises, agricultural product logistics projects, and integrated rural-urban distribution projects.

Under the plan, the government is (i) encouraging enterprises to expand their business services in rural areas; (ii) establishing a rural system for agricultural-product quality grading, postharvest handling, packaging, and distribution; and (iii) increasing the intensity of information technology (IT) penetration into pilot villages, including the creation of e-commerce platforms. ${ }^{9}$

On November 2015, the State Council published the Directive on Rural E-Commerce Development, which enables market mechanisms to play a more important role in accelerating the development of rural e-commerce, for instance, by combining existing village shops with e-commerce operators; promoting domestic consumption; and bolstering agriculture, rural development, and farmers' incomes. The directive also encourages the building of a platform-type network and the promotion of collaboration among e-businesses, parcel express companies, logistics service providers, traders, financial institutions, supply and marketing enterprises, and the postal service - to speed up the development of a rural logistics system. ${ }^{10}$

In December 2015, the State Council issued the Guidance on Advancing the Integrated Development of Tier 1, 2 and 3 Industries in Rural Areas. This document stated that, by 2020 , there must be visible progress in the integrated development of rural areas. Rural supply chains must be complete, multifunctional, and diverse, with the interest of the participants closely aligned to achieve a high degree of competitiveness. Farmers' incomes should continue to increase and rural vitality should have been significantly enhanced. This document stresses the principle of "internet plus modern agriculture" in developing agricultural e-commerce, as well as the importance of developing agricultural product processing and building connections between highly productive agricultural areas and key logistics nodes. The document also urges enterprises to improve the agricultural marketing system that matches buyers with sellers, including the establishment of direct sales outlets for fresh agricultural products in urban communities. ${ }^{11}$

\footnotetext{
8 Government of the People's Republic of China, State Council. 2012. Opinions on Deepening the Reform of Distribution System to Expedite Development of Distribution Industry. No. 39. Beijing.

9 Government of the People's Republic of China, National Development and Reform Commission. 2014. Medium- and Long-Term Plan for Development of Logistics Industry. No. 42. Beijing.

10 Government of the People's Republic of China, State Council. 2015. State Council Directive on Rural E-Commerce Development. No. 78. Beijing.

${ }^{11}$ Government of the People's Republic of China, State Council. 2015. Guidance on Advancing the Integrated Development of Tier 1, 2 and 3 Industries in Rural Areas. No. 78. Beijing.
} 


\section{A Review of Ministry-Level Rural Logistics Policies and Measures}

Since 2010, the Ministry of Agriculture, the Ministry of Commerce, the Ministry of Transport, China Co-op, and the State Post Bureau have issued many policies and measures related to rural logistics. They cover seven key areas: (i) rural logistics infrastructure, (ii) a rural logistics network system, (iii) rural logistics operators, (iv) rural logistics operating models, (v) rural logistics equipment, (vi) rural logistics informatization, and (vii) rural logistics policy management.

The Ministry of Commerce, jointly with the Ministry of Finance, issued a policy in 2009 that entailed

(i) supporting the construction and renovation of 200 large wholesale markets for fresh agricultural products in key sales and production areas in 2009;

(ii) encouraging markets to establish close contacts with farmers;

(iii) improving the level of marketing services;

(iv) supporting the standardized construction and renovation of 400 free farmers' markets at the county or township level;

(v) improving trading facilities and the trading environment;

(vi) gradually establishing a circulation system for agricultural products centered on wholesale markets and free farmers' markets in urban and rural areas;

(vii) lowering the cost of circulation, reducing the loss of agricultural products, expanding distribution channels, and overcoming the difficulties in selling agricultural products; and

(viii) guaranteeing urban and rural residents "safe-to-eat vegetables."12

The policy also called for building wholesale markets; revamping quasi-public wholesale markets so they could provide cold storage and transport; promoting food chain quality and traceability; strengthening food safety monitoring and waste disposal; and creating facilities for agricultural product trading, logistics, processing, distribution, sorting, and packaging.

Furthermore, in 2015, the Ministry of Finance and the Ministry of Commerce announced a policy that included building a sound rural e-commerce service system, expanding the range of rural e-commerce applications, raising rural e-commerce capability, and improving the environment for growing rural e-commerce. The policy specified key initiatives that will be receiving financial support from the central government:

(i) the establishment of a three-tier (county, township, and village) distribution system;

12 Government of the People's Republic of China, Ministry of Commerce and Ministry of Finance. 2009. Notice on Accelerating the Construction of Agricultural Product Circulation Network and Promoting the Project of '100 Large Agricultural Product Wholesale Markets and 100 Large Agricultural Product Circulation Enterprises.' No. 277. Beijing. 
(ii) the encouragement of a wide variety of transport and logistics operators (such as State Post Bureau, China Co-op, third-party logistics operators, and local logistics enterprises) to compete in offering solutions to rural e-commerce challenges;

(iii) support for the creation of public county-level e-commerce service centers and village-level e-commerce service outlets; and

(iv) support for a branding and quality-guarantee program aimed at farm produce and goods produced in rural areas, so as to nurture rural e-commerce..$^{13}$

Table 1 identifies the major policies and measures by three government agencies with regard to the seven key areas of rural logistics: infrastructure, networks, operators, operating models, equipment, informatization, and policy management.

\section{Table 1: Major Policies and Measures by Government Agencies regarding the Seven Key Areas of Rural Logistics}

\begin{tabular}{|c|c|c|c|}
\hline Key Areas & Ministry of Agriculture & $\begin{array}{l}\text { Ministry of Transport } \\
\text { and State Post Bureau }\end{array}$ & China Co-op \\
\hline Infrastructure & $\begin{array}{l}\text { Promote and coordinate } \\
\text { the development of a new } \\
\text { phase of the "shopping } \\
\text { basket program," which } \\
\text { will incorporate a large } \\
\text { variety of products, and } \\
\text { will address the desire for } \\
\text { fresh farm produce, the } \\
\text { large volume of cross- } \\
\text { regional circulation, and } \\
\text { many issues concerning } \\
\text { out-of-season sales }\end{array}$ & $\begin{array}{l}\text { Collectively plan and build logistics parks } \\
\text { that will offer comprehensive services } \\
\text { such as the circulation, processing, } \\
\text { storage, transport, and distribution of } \\
\text { agricultural products } \\
\text { Strengthen the coherence of the planning } \\
\text { for the development of a marketing } \\
\text { system for domestic agricultural products } \\
\text { Promote the construction of rural postal } \\
\text { infrastructure in the townships with } \\
\text { no postal services, and strengthen the } \\
\text { connection among rural postal logistics } \\
\text { facilities, local logistics parks, and rural } \\
\text { logistics and distribution centers }\end{array}$ & $\begin{array}{l}\text { Strengthen the } \\
\text { decentralized service } \\
\text { network by relocating } \\
\text { and consolidating } \\
\text { isolated service outlets }\end{array}$ \\
\hline Networks & $\begin{array}{l}\text { Plan and establish a } \\
\text { storage system suitable } \\
\text { for fresh agricultural } \\
\text { produce }\end{array}$ & $\begin{array}{l}\text { Strengthen rural-logistics-infrastructure } \\
\text { planning for transportation, agriculture, } \\
\text { farm supply and marketing, postal } \\
\text { services, and parcel express services to } \\
\text { achieve a well-coordinated network for } \\
\text { resource sharing and development } \\
\text { Improve the rural-logistics-infrastructure } \\
\text { network by establishing rural logistics } \\
\text { hubs supported by logistics nodes at the } \\
\text { county, township, and village levels } \\
\text { Develop a rural postal-distribution- } \\
\text { logistics network }\end{array}$ & $\begin{array}{l}\text { Build a three-level } \\
\text { (county, township, and } \\
\text { village) management } \\
\text { network that will } \\
\text { include distribution } \\
\text { centers at the county } \\
\text { level and centralized } \\
\text { supermarkets at } \\
\text { the township level; } \\
\text { and expedite the } \\
\text { construction of } \\
\text { convenience stores, } \\
\text { agricultural-product } \\
\text { sales outlets, and } \\
\text { recycling stations at the } \\
\text { village level }\end{array}$ \\
\hline
\end{tabular}

continued on next page

13 Government of the People's Republic of China, Ministry of Commerce and Ministry of Finance. 2015. The 2015 Notice on Developing Comprehensive Demonstration of E-Commerce Entering Rural Areas. No. 60. Beijing. 
Table 1 continued

\begin{tabular}{|c|c|c|c|}
\hline Key Areas & Ministry of Agriculture & $\begin{array}{l}\text { Ministry of Transport } \\
\text { and State Post Bureau }\end{array}$ & China Co-op \\
\hline Operators & $\begin{array}{l}\text { Actively support } \\
\text { participation in } \\
\text { agricultural-product } \\
\text { circulation by } \\
\text { strengthening the training } \\
\text { of agricultural-wholesale- } \\
\text { market general managers, } \\
\text { agricultural-product } \\
\text { dealers, and agricultural } \\
\text { brokers }\end{array}$ & $\begin{array}{l}\text { Promote an advanced rural-logistics } \\
\text { operations mode consisting, for instance, } \\
\text { of one outlet with multiple functions } \\
\text { and one network for multiple purposes } \\
\text { to enable the sharing of complementary } \\
\text { resources, risks, and benefits } \\
\text { Explore new mechanisms for cross- } \\
\text { sector construction and management, } \\
\text { and for cross-industry cooperation and } \\
\text { development } \\
\text { Vigorously support private shipping } \\
\text { companies as part of rural postal logistics } \\
\text { development } \\
\text { Focus on creating an integrated } \\
\text { service platform with comprehensive } \\
\text { management, scale, and community- } \\
\text { oriented services }\end{array}$ & $\begin{array}{l}\text { Promote the } \\
\text { development or reform } \\
\text { of cooperative-owned } \\
\text { enterprises; also help } \\
\text { leading enterprises } \\
\text { enhance their } \\
\text { capacity to innovate } \\
\text { and compete, and } \\
\text { encourage them to } \\
\text { grow into key players } \\
\text { in new agricultural } \\
\text { networks }\end{array}$ \\
\hline Operating models & $\begin{array}{l}\text { Focus on three policies: } \\
\text { (i) developing direct } \\
\text { distribution capabilities } \\
\text { in order to stabilize } \\
\text { sales channels, (ii) use } \\
\text { networks to match sellers } \\
\text { and buyers, and (iii) } \\
\text { explore the possibility of } \\
\text { developing e-commerce } \\
\text { for agricultural products }\end{array}$ & $\begin{array}{l}\text { Vigorously develop express logistics } \\
\text { services in rural areas } \\
\text { Support the role of private shipping } \\
\text { companies in providing chain distribution } \\
\text { services for agricultural inputs, consumer } \\
\text { goods, pharmaceutical products, and } \\
\text { primary and secondary school textbooks } \\
\text { Support the expansion of services } \\
\text { distributing agricultural byproducts to } \\
\text { urban areas }\end{array}$ & $\begin{array}{l}\text { Expedite China Co-op's } \\
\text { e-commerce development } \\
\text { so that it can fully use } \\
\text { the capabilities of major } \\
\text { distribution enterprises, } \\
\text { commodity trading } \\
\text { markets, and agricultural } \\
\text { wholesale markets to build } \\
\text { B2B e-commerce trading } \\
\text { platforms and to expand } \\
\text { online sales of agricultural } \\
\text { inputs, agricultural } \\
\text { products, and consumer } \\
\text { goods }\end{array}$ \\
\hline Equipment & & $\begin{array}{l}\text { Promote the use of affordable vehicles } \\
\text { for rural logistics } \\
\text { Establish technical standards for } \\
\text { vehicles used in rural logistics that meet } \\
\text { development needs and are suitable for } \\
\text { rural roads } \\
\text { Raise the level of rural-logistics } \\
\text { equipment and facilities to professional } \\
\text { standards } \\
\text { Promote the use of pallets, container } \\
\text { baskets, cage carts, and other } \\
\text { standardized material-handling } \\
\text { equipment in rural logistics-as well as } \\
\text { specialized packing, sorting, loading, and } \\
\text { unloading of equipment-to improve } \\
\text { operational efficiency and reduce cargo } \\
\text { loss and damage }\end{array}$ & \\
\hline
\end{tabular}


Table 1 continued

\begin{tabular}{|c|c|c|c|}
\hline Key Areas & Ministry of Agriculture & $\begin{array}{l}\text { Ministry of Transport } \\
\text { and State Post Bureau }\end{array}$ & China Co-op \\
\hline Informatization & $\begin{array}{l}\text { Make the agricultural } \\
\text { information system more } \\
\text { comprehensive }\end{array}$ & $\begin{array}{l}\text { Improve the level of rural logistics } \\
\text { informatization } \\
\text { Regarding the transport-information- } \\
\text { management system for the county-level } \\
\text { traffic and transport authorities, integrate } \\
\text { the information resources of China } \\
\text { Co-op, postal service, and other related } \\
\text { agencies } \\
\text { Effectively combine the information } \\
\text { systems of agricultural-input } \\
\text { and agricultural-product dealers, } \\
\text { intermediaries, and logistics } \\
\text { enterprises-to build a county-level rural } \\
\text { logistics information platform that could } \\
\text { collect, analyze, and release information } \\
\text { on supply and demand. } \\
\text { Improve the level of informatization for } \\
\text { express delivery services in the central } \\
\text { region of the People's Republic of China } \\
\text { Encourage qualified express companies } \\
\text { to provide handheld PDA devices at town } \\
\text { and village outlets, and to equip their } \\
\text { information systems with connections to } \\
\text { enable real-time tracking and tracing }\end{array}$ & $\begin{array}{l}\text { Promote } \\
\text { informatization } \\
\text { by computerizing } \\
\text { financial accounting, } \\
\text { the management of } \\
\text { cooperatives, and } \\
\text { product marketing (via } \\
\text { the internet) } \\
\text { Encourage farmers' } \\
\text { cooperatives to } \\
\text { establish websites } \\
\text { and text messaging } \\
\text { platforms for sharing } \\
\text { production technology, } \\
\text { market information, } \\
\text { and discussions of } \\
\text { major issues and } \\
\text { day-to-day operating } \\
\text { conditions to make } \\
\text { farmers better informed } \\
\text { and more productive }\end{array}$ \\
\hline Policy management & $\begin{array}{l}\text { Implement supporting } \\
\text { policies and optimize } \\
\text { the environment for } \\
\text { improved circulation; hold } \\
\text { agricultural conferences } \\
\text { and exhibitions; expand } \\
\text { cooperation and } \\
\text { exchanges; investigate } \\
\text { the outcome of } \\
\text { the green channel } \\
\text { policya and promote } \\
\text { the management of } \\
\text { agricultural-product } \\
\text { circulation, based on } \\
\text { industry classifications }\end{array}$ & & \\
\hline
\end{tabular}

B2B = business-to-business, PDA = personal digital assistant.

a The green channel policy referred to in this table concerns government measures to facilitate the delivery of fresh and live farm products.

Source: Asian Development Bank. 


\section{Weaknesses in Policy Implementation}

\section{Insufficient Coordination in Logistics Planning}

Rural logistics planning involves multiple agencies, as described above. Each agency issues its own plans and policies and pursues its own goals; and there is no single government unit responsible for overall planning and coordination. As a result, rural logistics remains in a fragmented state, with a silo mentality pervasive across government agencies.

The result has been a suboptimization of the entire rural logistics system, leading to less comprehensive logistics network outlets, a lack of attention to sustainability, insufficient room for development, and redundant facility construction. At the same time, due to existing administrative boundaries and inadequate experience in developing and implementing reforms, a smoothly functioning unified rural logistics network has not yet been realized.

\section{Uneven Rural Logistics Network Development}

Because of uneven development across the country, there is a lot of variation in the capabilities of rural logistics networks. Economically developed areas such as Beijing, Tianjin, Hebei Province, the Yangtze River Delta, and the Pearl River Delta already have highperformance networks, and major agricultural provinces such as Shandong and Henan have adequate networks, but the remaining areas are lagging behind. In the less-developed areas, rural freight facilities are mainly owned by individual operators, and are characterized by inadequate infrastructure, small size, low coverage, limited functions, and loose management.

This situation makes it difficult for rural freight stations to effectively play their role in agricultural product transportation. The serious shortage of modern warehouses (including for cold storage) and other logistics facilities translates into a lack of transit storage for many agricultural products. The consequences are especially bad for fresh farm produce because it requires prompt chilling after harvest and temperature-controlled storage, whereas most existing facilities can only provide ambient-temperature storage.

\section{The Lack of Large Professional Transport Enterprises}

Most of the rural logistics operators are small and medium-sized enterprises that are owneroperated. Rural logistics is intrinsically hindered by low freight density and by the excessive fragmentation among participants, making efficiency difficult to achieve and leading to high transportation costs, relentless competitive pressure, and a lack of capacity for enterprise development.

Meanwhile, due to the weak supervision of the rural transport market, and to the lack of policies for fostering enterprise growth and strong price competition, many rural transport enterprises rely on illegal overloading to stay afloat. This has made it possible for the bad carriers to drive out the good carriers. The resulting deterioration in operating standards has greatly affected the market and limited the growth of efficient and competitive operators. 


\section{The Lack of Proper Vehicles and Material-Handling Equipment}

Modern transport equipment is not widely used in rural areas. To save costs, many antiquated and illegally modified farm vehicles are used in rural transport. This causes poor service quality, compromises safety, and makes the supervision of rural logistics difficult.

The serious shortage of refrigerated trucks and other specialized vehicles needed for agricultural product transport, as well as the lack of food-preservation equipment, often leads to severe spoilage of farm products during transportation, especially of perishable vegetables, fruits, and other temperature-sensitive agricultural products. In addition, because vehicle technical standards have not yet been established, and packaging standards do not support transport standards, rural agricultural-product transport is out of step with production and sales needs.

\section{The Inadequate Application of Technology}

There is a general shortage of electronic payment systems and public information platforms in rural locales. Trade is still based on cash and carry, with the commodities in hand. Few modern trading channels, such as online auctions and futures contracts, are used in rural areas. For many years, farmers have suffered from poor access to supply and demand information, inadequate transport capacity, seriously delayed or inaccurate information, sluggish transfers of data, and poor logistics services and capacity provisioning. It is therefore difficult for most farmers to know the best time for selling their products or for purchasing farm inputs.

To better understand and identify the improvements needed for the development and logistics of agricultural value chains, the Asian Development Bank conducted a study on the tomato value chain from Shandong to Beijing. Tomatoes were chosen because they have several characteristics: (i) they are strategically important for food security and farmer's incomes in the PRC; (ii) they require long-distance transporting; and (iii) with regard to tomatoes, there is a substantial demand for investments by value chain actors to meet quality and safety standards, reduce transaction costs and wastage, and increase yields. Box 2 describes the key findings of the study and their policy implications. 


\section{Box 2: The Case of the Fresh Tomato Value Chain from Shandong to Beijing}

\section{Key Findings and Policy Implications}

The objective of this case study was to gain a better understanding of the links involving logistics, transportation, and retail tomato prices. The following chart shows how the tomato value chain from Shandong to Beijing generally works.

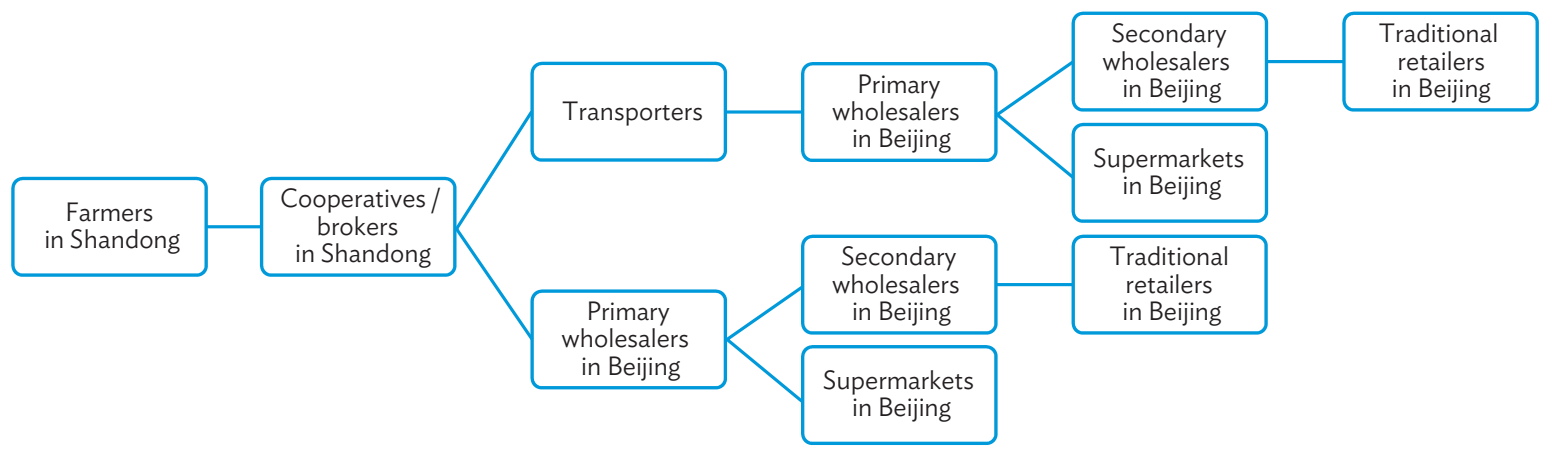

Three variations of the tomato value chain from Shandong Province to Beijing are typically observed, based on who is doing the transporting: traditional (farmers to wholesalers to retailers), semi-traditional (farmers to self-employed shippers to retailers), and modern (farmers to specialized shippers to supermarkets). Tomatoes are usually bought for CNY3 per kilogram in the cities of Zibo or Shouguang, and then sold in Beijing for CNY7.60 in wet markets, or for CNY10.50 at supermarkets. In an effort to collect first-hand information, a team from the Asian Development Bank conducted in-depth interviews from May to August 2015 with 38 actors at various points along these chains. Selected key findings and related policy implications are summarized as follows:

\section{Key Findings}

Policy Implications

Farmers, traders, transporters, and retailers participating in the tomato value chain are very small operators.

A profit margin of about two-thirds is added beyond farm-gate price, and retailers earn the highest gross margins: $47 \%$ or more.

Logistics costs account for close to $20 \%$ of the final tomato prices, but the major component of the costs are the retail markups in Beijing.

Transportation accounts for about $37 \%-53 \%$ of the logistics costs, although the "green channel policy" helps to reduce the total costs of line transportation from Shandong to Beijing by roughly $57 \%$.

Supermarkets encounter the highest last-mile logistics and transportation costs, but they have the lowest line transportation costs, compared with those of the traditional and semi-traditional variations of the chain.
The tomato value chain (and perhaps other produce value chains) should be made more inclusive of small operators through an alliance of cooperatives.

Measures related to post-farm-gate prices, particularly retail prices, should be developed to reduce the final fresh-produce prices for consumers.

Measures should be adopted to reduce the logistics costs and retail markups associated with fresh produce.

The green channel policy, which promotes easier movement of agricultural products, should be continued to help reduce the costs of fresh produce for the consumer at the end of the chain.

The development of specialized transporters should be encouraged to increase efficiency.

A favorable business environment should be fostered to keep the cargo movements running smoothly, without any delays caused by heavy traffic in urban areas. Better city planning would also help. 
Box 2 continued

\section{Key Findings}

Most the self-employed shippers have been fined for overloading or other violations.

Of the self-employed shippers, just over 83\% lacked sufficient backhaul cargo for the return trips to Shandong after delivering their tomato cargo in Beijing.

\section{Policy Implications}

There should be a clarification of the roles of various government agencies to reduce the occurrence of conflicting rules, inconsistent standards, and irregular enforcement at various levels.

Rural transport centers should be established at agricultural-produce consolidation points to reduce empty backhauls.

Source: Chen, Hu, and Lin. 2015. A Case Study: A Value Chain of Fresh Tomato from Shandong to Beijing. The final report submitted under the Asian Development Bank (ADB) Technical Assistance for Strategy and Transport Policy Study on Promoting Logistics Development in Rural Areas. Manila: ADB. 


\title{
III. INFORMATION TECHNOLOGY AND RURAL LOGISTICS
}

\begin{abstract}
- he internet is an efficient and effective facilitator of trade. E-commerce enables buyers to purchase directly from sellers. Along with the growth of the PRC's parcel express industry, e-commerce has greatly shortened the intervals along the supply chains. And with the internet now reaching almost every village, the radical reduction in supply chain intermediation has eased the sale of farm products directly to the consumers and allowed villagers to keep more of the sales proceeds as income. The efficient application of e-commerce can reduce the prices of consumer products and farm inputs, thereby extending the villagers' purchasing power further. Higher incomes and lower prices can together enhance the standard of living of rural residents.
\end{abstract}

At present, many problems in traditional supply-chain management have severely restricted farmers' market competitiveness. For example, in the vertically integrated supply-chain management model, too much emphasis is placed on competition, while cooperation is ignored, as is the need for information platforms and e-delivery methods. The emergence of e-commerce has caused fundamental transformations in the supply chain model; and, to some extent, it will correct the abovementioned shortcomings of the traditional supplychain model.

E-commerce supply-chain management makes extensive use of enterprise-resourceplanning systems, integrating nearly all the aspects of management (human resources, finance, materials, production, supply, and marketing) to standardize the company's basic information and business processes. As a result, a company can establish an e-collaborative platform to make its operations fully efficient and increase its market reach.

\section{A. E-commerce Trends in Rural Areas}

\section{Rural E-commerce Value and Volume}

While urban e-commerce has reached near saturation, rural online shopping has become a new driver of growth. According to the PRC Ministry of Commerce, the PRC's e-commerce sales in 2016 were worth CNY5.2 trillion, with year-on-year growth of $26.2 \%$, double the growth rate of total retail sales. Figure 3 shows that the transaction value of online retail in rural areas nearly doubled from 2014 to 2015 , only to grow by another $253 \%$ to CNY894 billion in 2016, clearly exceeding year-on-year growth of urban online retail. 
Figure 3: Rural E-Commerce Transaction Value, 2014-2016

CNY billion

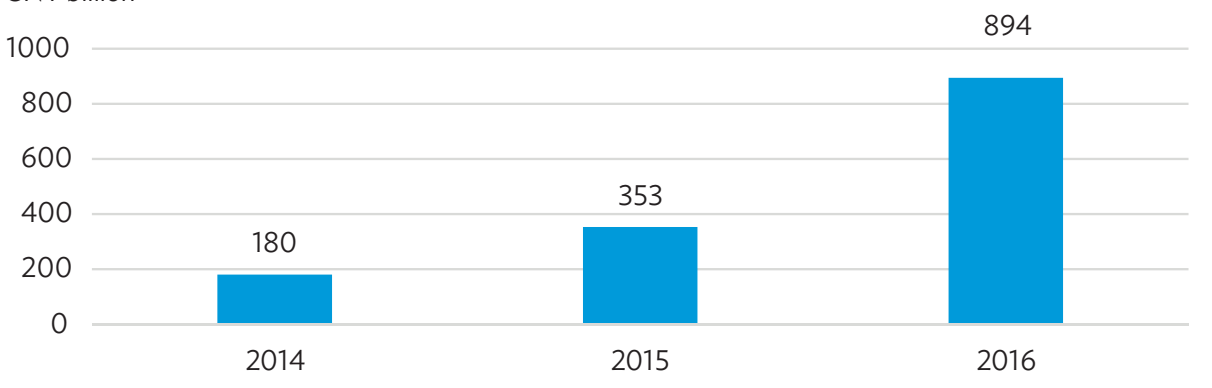

Source: Government of the People's Republic of China, Ministry of Commerce, China International Electronic Commerce Center.

Among the population of consumers shopping online, the group of rural consumers has been growing steadily. Year-on-year growth reached as much as 41\% in 2014, compared with $16 \%$ growth among the urban consumer group (Figure 4).

Figure 4: Comparison of Rural and Urban Online Consumer Growth Year-on-Year, 2010-2015

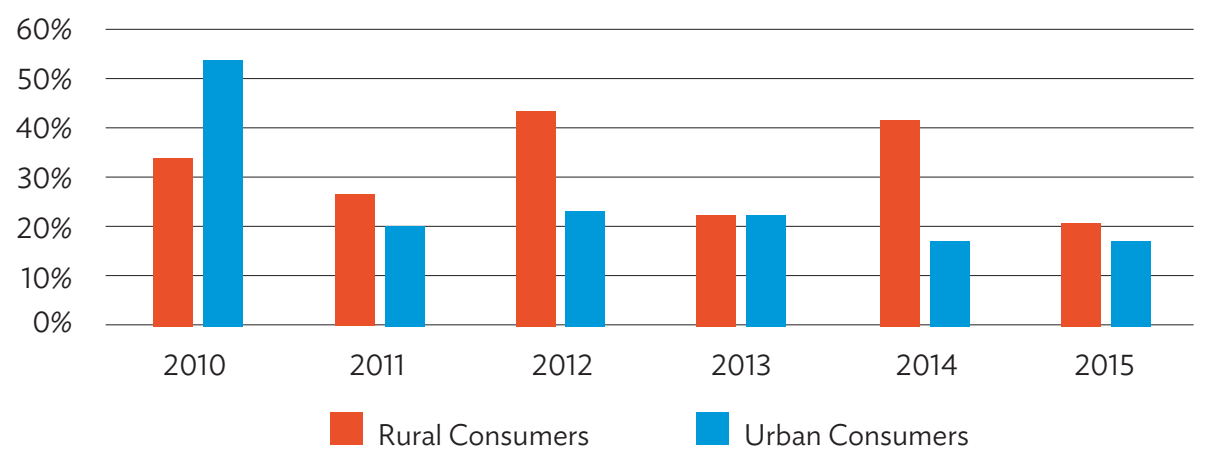

Source: China Internet Network Information Center.

As of December 2015, 92 million (47\%) of the 195 million rural internet users had shopped online. However, this still accounts for only 15\% of the 622 million people living in the countryside. According to McKinsey's 2015 China Digital Consumer Survey Report, 66\% of Tiers 3 and 4 city internet users, and $72 \%$ of Tiers 1 and 2 city internet users shopped online. A notable fact is that "rural online consumers" does not only mean farmers, but also a great number of people who are either in construction, mining, or also the service economy.

In terms of geographical distribution, most rural consumers still come from the rather developed coastal provinces of the PRC, with Jiangsu leading with 9\% (2016). Together with consumers from the countryside of Hebei, Zhejiang, Shandong, and Guangdong, 
and the inland provinces of Sichuan and Henan, more than $50 \%$ of rural e-commerce is concentrated in only seven provinces. The Report on the Rural E-Commerce Consumer Trends 2016 shows further that not even 1\% of online orders came from rural Qinghai, Gansu, and Tibet Autonomous Region.

\section{High Value Density Products Leading}

As of August 2016, the most sought-after consumer goods in rural online retail were computer, communication, and consumer electronics. With nearly a third of online orders from the countryside, mobile phones ranked first. Computers and other electronics made up $20 \%$. Clothing accounted for $13 \%$ of goods sold, followed in decreasing proportion by supplies for infants, sports equipment, cosmetics, foodstuffs, footwear, furniture and house fittings, and jewelry.

While there is a huge offline market for material used in agricultural production, it is still the segment that is the most underdeveloped in rural e-commerce, yet as well the one with big potential. In 2015, rural online sales rocketed the first time to CNY150 billion, six times the value of the previous year.

Among the agricultural products going to the urban centers via retail in 2016, fruits, tea, herbal medicine, grain and oil, nuts, and animal products were the most purchased, with the first three representing more than half of all agricultural products sold. The online retail market for fruits has grown the fastest and, by purchase value, accounted for a proportion of $22 \%$. With a high value density and low logistics cost, tea ranked second (19\%) followed by herbal medicine (15\%). Other agricultural products still face higher logistics cost or technical constraints to gain ground.

According to China Rural E-Commerce Development Report (2015-2016), rural areas with a relatively strong industry basis on county level developed an advantage in the production and consequently online retail of house fittings. This is mostly the case for Jiangsu and the other coastal provinces.

From central and western provinces, rurally produced foodstuffs, often local specialties, and herbal medicine are the most numerous in online retail.

\section{B. The Rapid Development of Parcel Express Companies}

Supported by the rapid rise of e-commerce, the PRC's parcel express industry grew at breakneck speed. From 1 billion parcels a year at the start of the 2006 postal reform, ${ }^{14}$ total volume grew to 14 billion parcels in 2014. Shengtong Express rode the e-commerce wave to become the largest parcel express company in the PRC. Its growth can be largely attributed to its special partnership with Alibaba, the world's largest e-commerce company. The PRC's parcel-express volume now exceeds that of the United States, and is ranked the largest in the world by volume. However, due to the low average rate per package (CNY14.50), the PRC's parcel express market is still below that of the United States in terms of revenue.

Generally, the service quality of Chinese parcel-express companies is low, far from the stringent standards set by global express companies such as FedEx, UPS, TNT, and DHL.

14 The PRC's postal system reform in 2006 accomplished the separation of government functions and enterprise management. 
The need for improvement is shown by the fact that Chinese parcel-express companies have a dismal share of the international express-delivery market. Their low market share is due to the following reasons:

(i) A highly fragmented domestic market populated by many small operators limits the prices that can be charged for providing quality service. Thus, local parcel express companies cannot afford to meet the service standard required to compete in the international parcel-express market.

(ii) Low profit margins mean insufficient funds for investment in network expansion; and without a global network, local parcel carriers cannot meet the coverage requirements met by large multinational companies.

(iii) Low profit margins also mean insufficient funds for service upgrades, capacity expansion, and personnel training.

(iv) The dominance of foreign markets by strong, capable, and well-funded parcel express companies creates a tough barrier to entry.

By improving the use of information and communication technology, one could implement an integrated information management process for logistics systems. However, the current level of information systems cannot meet current needs.

\section{Players and Platforms Entering Rural E-Commerce and Logistics}

As key e-commerce players in the PRC, Alibaba and JingDong (JD.com) have already taken decisive steps to expand their sales networks into rural areas as "e-tailer of choice." In 2014, Alibaba initiated its "100 counties, 1,000 townships, 10,000 villages" rural expansion strategy, involving an investment of CNY10 billion to build an e-commerce network covering 100 counties, 1,000 townships, and 100,000 administrative villages-accounting for $70 \%$ of the rural population - within 3-5 years. The Ali Research Institute's mid-2016 Taobao Village Study indicates that, by June 2016, Alibaba had already established 1,311 so-called "Taobao Villages" county service centers in 18 provinces to create logistics channels for delivering "consumer goods to the countryside" and "agricultural goods to urban areas." Guandong, Zhejiang, and Jiangsu are the top three ranked provinces in this development. Taobao Villages alone were the point of origin for 700 million packages sent in 2016.

The strategy Alibaba pursues is to enter the rural market by building partnerships with local sellers who wish to expand their market presence. These are clustered into the Taobao Villages and products are sold via Alibaba's Taobao marketplace. Where a Taobao Village has been established, an average $10 \%$ of families in the village have their own online shop, with an aggregate turnover per village of CNY10 million annually.

Another pioneer in rural e-commerce, JingDong has been actively expanding its rural coverage. According to the company, by the end of 2015, it had established nearly 700 county service centers to extend its rural distribution coverage and assist villagers with online shopping. Meanwhile, JingDong has established "JD Gang" service shops in over 1,200 counties, covering about 350,000 administrative villages, to facilitate sales, distribution, installation, and the maintenance and repair of large home appliances. In addition, it 
cooperated with county and city governments, and with 478 agriculture enterprises, to establish the "JD Special Products Shops" to sell agricultural products to urban consumers. A partnership with Grameen Trust provides for microloans for rural entrepreneurs completes the service package of JingDong.

Relying on the rural passenger transport network, the "freight and village bus network" model is expanding as a means of extending freight transport to small villages. Huawei Logistics, a company based in Yichang, utilized integrated rural-transport service stations and other convenience facilities as logistics service stations in 12 township locations. It used 10 freight vehicles to start six freight services with fixed schedules, fixed stops, and fixed routes to connect the county with surrounding townships. It also established alliances with rural passenger bus operators, extending its services through the coverage offered by over 600 passenger buses. At present, Huawei is working with three parcel express companies, four agricultural supply enterprises, two trading companies, and two integrated rural transport service stations to further extend its services into rural areas.

JingDong and Alibaba have adopted opposite approaches to penetrating rural markets. JingDong uses an asset-intensive approach based on company-owned fulfillment centers, warehouses, logistics hubs, and company vehicles. In contrast, Alibaba employs an asset-light approach, focusing on developing an information technology (IT) platform ("Cainiao") that efficiently links various logistics providers together so they can deliver end-to-end service.

Each approach has its own advantages and disadvantages. For example, JingDong's approach ensures higher service quality, but consumes large amounts of capital. Alibaba's approach is more flexible, more agile, and less costly, but the service quality is less consistent.

The companies' experience so far does not lead to any definitive conclusion as to which approach should be embraced by the government. An appropriate solution might be to adopt JingDong's approach in the more developed rural areas and Alibaba's approach in the less developed rural areas, making use of already established transport networks operated by the State Post Bureau and rural bus services.

In the United States, Amazon has always outsourced its product deliveries, but it is beginning to develop its own logistics network, acquiring planes, trucks, and equipment to support high-density routes. However, it still intends to outsource deliveries during peak traffic or over less dense routes to companies such as UPS and FedEx, or to the US Postal Service.

After JingDong, another leader from offline retailing has found its way into rural e-commerce: Suning. Suning combines a direct online platform, financial service centers, and an Online2-Offline model. Specialized rural produce business-to-business (B2B) and business-tobusiness-to-consumer (B2B2C) e-commerce platforms provide coordinated sourcing opportunities together with delivery services for restaurants, whereas producers of material used in agricultural production develop their own online markets.

\section{Drivers and Bottlenecks of Rural E-Commerce}

Rural e-commerce is a bidirectional online service. On the one hand, it enables the rural population to enjoy goods and services formerly only accessible to urban residents. On the other hand, it provides a means for individual producers from the countryside to access a much larger market. An example of an application of e-commerce and direct selling is shown in Box 3. 
Without the presence of large brands in physical location, e-commerce offers shoppers the possibility to access them, have them delivered, and compare prices. Convenience and choice are two of the key points in the expansion of rural online retail. Another is the increase in rural average income per capita, still expanding at a higher growth rate than the GDP. Consequently, the prospect of e-commerce further expanding into rural areas is a promising one. However, some aspects are worth considering.

\section{Internet Accessibility and the Ubiquitous Use of Smartphones}

Up until today, only a third of the rural population in the PRC is connected to the internet, and only a sixth uses online retail. Connectivity and interrupted electricity to power computers are still among the more notable constraints on the further development of rural e-commerce. But ambitious plans to extend internet access nationwide by 2020 will render this problem obsolete and further growth can be expected.

Moreover, the PRC is at the epicenter of smartphone development, not only as the world's manufacturer of smartphones, but also as a leading innovator in creating affordable, highperformance smartphones, with Xiaomi and Huawei as prime examples. The affordability of Chinese smartphones and their adaptability to local needs means that they are ubiquitous throughout the country, even in rural areas. As of July 2017, 780 million people in the PRC use the mobile phone to access the internet.

The surge in smartphone use has ushered in the era of mobile commerce in the PRC. "M-commerce," or mobile e-commerce, consists of the buying and selling of goods and services through wireless handheld devices, particularly smartphones. In contrast to traditional e-commerce, $\mathrm{m}$-commerce enables business-to-business (B2B) or businessto-consumer (B2C) commerce to be conducted on the go. M-commerce enables the consumers to shop online anytime and anywhere, using mobile telecommunication signals.

Mobile e-payment is another prominent development that drives rural e-commerce. New mobile payment platforms, such as Alipay or WeChat Pay, have become available to any user of a smartphone or other mobile device, whether in dense cities or remote rural areas.

\section{Box 3: The Lingjiatang Wholesale Market's Fresh-Food Delivery Service}

In August 2012, the wholesale market in the town of Lingjiatang (Jiangsu Province) established the Lingjiatang E-Commerce Company, which operates through e-commerce and direct selling, and uses innovative ways to ship fresh agricultural products. The wholesale market invested over CNY5 million to set up the "Wanjiaxian" fresh food retail website (www.wanjiaxian.com), as well as a platform for providing direct supplies of fresh food. The objective was to promote the direct selling and supply of fresh agricultural products. The specific actions included the following:

(i) The establishment of a fresh food distribution center: The Lingjiatang E-Commerce Company built a fresh food distribution center covering 1,400 square meters. The center consists of a goods-importing area, sorting area, processing area, distribution area, and fresh keeping warehouse. It is also equipped with processing facilities, such as a processing line, cleaning machine, and slicing machine, as well as transshipping facilities (including a stacker and hydraulic trailer). 
(ii) The setting up of groceries for the direct supply and selling of fresh produce: The first grocery was opened on Gufang Road, in the town of Hutang (Jiangsu Province). There are currently 6 groceries for direct selling and 20 stations for direct supply.

(iii) The practice of group delivery: Working people are an important market for agricultural products. To satisfy this demand, the Lingjiatang E-Commerce Company put a lot of effort into promoting group deliveries, and adheres to high standards with regard to purchasing, quality examination, processing, and distribution. The group delivery service currently covers more than 30 large enterprises, institutions, and government agencies.

The development of e-commerce, which combines online and offline activities: Through the Wanjiaxian e-commerce retailing website, customers can order food directly from the company or from community groceries. The website also collaborates with "Tanchangzhou," a local e-commerce platform. Wanjiaxian offers more than 500 commodities, with total daily sales reaching CNY20,000 during peak periods. Within a very short time after its founding, Wanjiaxian gained a considerable share of the fresh agricultural product market in the city of Changzhou (Jiangsu Province).

Source: Asian Development Bank.

\section{E-Commerce and Product Knowledge Development}

Research by Jiangxi University and the China Rural E-Commerce Development Report indicates that the countryside of the PRC is lacking specialized knowledge. Combined knowledge in IT, marketing, and logistics is needed to successfully develop e-commerce as a source of income. However, farmers who desire to promote their goods online themselves often a basic understanding of the market, trading platforms, and marketing tools and thus quickly run into a cost-trap. While professional training is encouraged, locals with higher education often choose not to return to their villages thus impairing a fresh inflow of ideas and knowledge. Grassroots associations seek to alleviate this situation by systematic and planned actions, while other local communities are driven through a process of discovery and learning by a pioneer e-tailer.

On the rural consumer side, knowledge of products and brands is gradually increasing and the rural population is less prone to buying fake or low-quality products than only a few years ago. Together with the consolidation of certain larger online retail platforms, this is leading to higher level of faith in the online marketplace. However, the captured research suggests that there is still considerable room for improvement, since this industry depends particularly on trust.

A vehicle to strengthen the confidence of the urban consumers buying rural produce online may be the promotion of geographical appellations for certain products.

\section{Geographical Denomination and Quality Certification}

Except for some local delicacies widely known throughout the country, there is a lack of brand consciousness for rural produce in the PRC. Fragmented production of a large variety of agricultural products, limited means of marketing, and limited means for certification have so far hampered the emergence of well-known regional specialty products of a certain standard. 
Thus, quality cannot be reflected through adequate pricing, and products originating from the countryside may only compete on the market via a low price. The gradual introduction of a system of geographical appellation protection, combined with quality control mechanisms, may remedy this problem.

\section{Imperfect Supply Chains}

Underdeveloped or nonexistent logistics infrastructure in rural areas and, consequently, higher logistics cost is still a major bottleneck for the rural e-commerce. Last-mile transport solutions are still missing for a large number of areas, and delivery or dispatch of goods relies heavily on rather cost-intensive express parcel services, if at all. Particular problems in this regard are the development of temperature-controlled supply chain systems and the integration of online and offline segments of e-commerce as this affects rural producers of perishable goods in tapping into the online market, where timely delivery and uninterrupted cold chains are crucial. Where transportation means exist, dispatching and collecting goods is mostly unorganized and does not make use of existing software solutions.

However, recent developments show that e-commerce is already causing the logistics industry to develop further (not least because of the entry of large e-commerce champions in the arena).

\section{E. The Impact of E-Commerce on the Agricultural Logistics Industry}

Because of the close relationship between e-commerce and logistics, the e-commerce revolution has a significant impact on the logistics industry. This impact is a comprehensive one, affecting the status, organizational structure, and all the functions of the logistics industry. E-commerce has inevitably a further impact on rural logistics performance as well.

Logistics companies are further increasing the importance of e-commerce, as it enables companies to serve, not only as warehouses for manufacturers, but also as suppliers for end users, providing them with comprehensive logistics services.

Through e-business, the supply chain has connected suppliers, retailers, and consumers via the internet. By using sales terminals (i.e., Point of Sale machines), vendors can promptly access accurate product and customer information. Further, inventory management can use the product and consumer information to ensure a flow of inventory based on the "pull" model, and thus achieving zero inventory. The introduction of these technologies in rural areas optimize logistic chains, enabling faster, cheaper, and more reliable services.

Increased demand and subsequent improvement of the logistics infrastructure and services environment on the one hand are improving the conditions for agricultural produce to expand into new markets. Effective and efficient distribution channels within rural areas and between rural and urban areas are on the rise. However, while the product flow to the countryside is providing capacity for agricultural produce to be shipped out to urban centers, supply-chain management has to be improved, especially in view of timely delivery of agricultural products of quality and value. Information technology already provides suitable solutions. 


\section{F. The Development and Application of Big Data Technologies}

Collecting electronic data from numerous sources and applying analytics to identify patterns and trends (big data analytics) can be tremendously useful. The analysis can identify patterns and trends that may not otherwise be easy to perceive, and can help a company predict what might happen in the future. In the context of supply chain management, big data involves analyzing data from point-of-sale systems, bar-code scanners, radio-frequency identification readers, global positioning system (GPS) devices in vehicles, and feeds from various logistics software systems and enterprise resource-planning systems.

The government is promoting the use of big data analytics as part of its "Industry 4.0" transformation. The demand for applications of big data analytics to logistics will surge as the PRC's economy moves up the value chain.

The logistics industry could improve its performance significantly by integrating different aspects of logistics resources-and thus different types of data-to optimize transport efficiency.

Big data technologies can enable the logistics industry to understand the needs and capacities of each transportation node, establish national logistics networks, deploy resources rationally, decrease empty-load truck return rates, decrease the duplication of transport routes, and reduce the proportion of transports of small-scale cargoes. Further, big data analytics can help gauge freight demand along different routes in a timely manner. Meanwhile, the identification of the locations of cargo containers relative to industrial-chainbased ports makes it possible for goods and logistics facilities to be optimally matched to improve transportation efficiency. This will ultimately generate higher value for the logistics companies, improving their incomes by optimizing resource allocations.

The use of big data technology in logistics management could reduce logistics costs and increase the value of goods due to scientifically based optimal decisions. Applying datamining technologies to logistics could strengthen the underlying system's functionalities, achieve logistics-industry structure adaptations, reduce labor inputs, increase market adaptability, and eventually contribute to an overall upgrade of the logistics industry.

\section{G. The Development and Application of Cloud Computing Technology}

Cloud computing is the provision of computing and storage services via the web on an asneeded basis through a subscription plan. Users share computing power, software, hardware, and data through a cloud-computing service provider such as Amazon or Alibaba. In addition to lower costs, the benefits to users include scalability, agility, elasticity, responsiveness, and speed.

Amazon Web Services, which provides cloud computing to thousands of private enterprises as well as to United States government departments and agencies (federal, state, and local), is the fastest-growing and most profitable part of Amazon. Cloud computing is an important enabling technology for logistics management, making it easier for logistics partners to share information and make joint decisions. The technology is especially useful for managing rural 
logistics, as the low traffic densities in rural areas means that more parties are involved in door-to-door transports.

In fact, the logistics industry cannot develop without logistics information systems (figure 5).

\begin{tabular}{|c|c|c|c|c|c|c|c|c|c|}
\hline \multicolumn{10}{|c|}{ Figure 5: The Logistics Information System } \\
\hline monitored layer & \multirow[t]{6}{*}{$\begin{array}{l}\text { system of laws and } \\
\text { regulations and } \\
\text { regulations } \\
\text { of logistics } \\
\text { informatization }\end{array}$} & $\begin{array}{l}\text { customs } \\
\text { CIQ }\end{array}$ & $\begin{array}{l}\text { traffic } \\
\text { monitor }\end{array}$ & $\begin{array}{l}\text { product } \\
\text { monitor }\end{array}$ & $\begin{array}{l}\text { information } \\
\text { security }\end{array}$ & $\begin{array}{l}\text { environmental } \\
\text { protection and } \\
\text { obtain } \\
\text { employment }\end{array}$ & $\begin{array}{l}\text { industrial and } \\
\text { commercial tax }\end{array}$ & $\begin{array}{l}\text { finance and } \\
\text { insurance }\end{array}$ & \multirow[t]{6}{*}{$\begin{array}{l}\text { standard } \\
\text { system and } \\
\text { safety } \\
\text { system of } \\
\text { logistics } \\
\text { informatization }\end{array}$} \\
\hline macro layer & & \multicolumn{2}{|c|}{\begin{tabular}{|l} 
international \\
logistics \\
informatization
\end{tabular}} & \multicolumn{2}{|c|}{$\begin{array}{l}\text { defense emergency logistics } \\
\text { informatization }\end{array}$} & \multicolumn{3}{|c|}{ multimodal transport of informatization } & \\
\hline meso layer & & \multicolumn{3}{|c|}{$\begin{array}{l}\text { key logistics industry } \\
\text { informatization }\end{array}$} & \multicolumn{2}{|c|}{ regional logistics informatization } & \multicolumn{2}{|c|}{ logistics park informatization } & \\
\hline microscopic layer & & \multicolumn{4}{|c|}{ enterprise logistics informatization } & \multicolumn{3}{|c|}{ logistics enterprise informatization } & \\
\hline base layer & & \multicolumn{3}{|c|}{$\begin{array}{l}\text { logistics infrastructure } \\
\text { informatization }\end{array}$} & \multicolumn{2}{|c|}{$\begin{array}{l}\text { logistics technical and equipment } \\
\text { informatization }\end{array}$} & \multicolumn{2}{|c|}{$\begin{array}{l}\text { logistics management } \\
\text { informatization }\end{array}$} & \\
\hline technology layer & & \multicolumn{4}{|c|}{ logistics related information industry } & \multicolumn{3}{|c|}{ logistics related information industry } & \\
\hline \multicolumn{10}{|c|}{$C I Q=$ China Inspection and Quarantine. } \\
\hline Source: Asian & evelopment $\mathrm{Ba}$ & & & & & & & & \\
\hline
\end{tabular}

With the support of laws, regulations, standards, and security systems related to logistics information systems, cloud computing plays a considerable role in the formation of multifunctional and multifaceted systems for facilitating information sharing between different functionalities and entities. After its full development in the future, cloud computing will be able to provide information for all levels of functionalities and entities, enter various types of information into logistics-related functional modules, share the logistics information fully and widely, and react to control and command modes in logistics operations, thus becoming the central component of any logistics information system.

The impact of cloud computing on express services mainly comes from the sharing of logistics information. Express service providers have established an industry-wide cloud to sort out delivery routes and make optimal choices of shipping companies to transport particular cargoes. During this process, cloud-based logistics integrates the receiving, shipping, and terminal distributions to consolidate bulk cargoes; improve the efficiency of the shipping companies; and, eventually, to reduce costs.

Other areas, such as vehicle loading and transportation-process monitoring, can also be facilitated by cloud computing. This technology can collect a wide range of information on the supply of goods and vehicles, and make distribution information publishable well before the actual shipments. It accelerates the distribution speed and improves loading rates. 
Through the use of mobile smart devices, goods in transit can be treated as virtual inventory, so they can be traded instantly and directly without third party interference.

Sensors, GPS, and geographic information systems (GISs) have penetrated many sectors of the PRC society, and will certainly have a large impact on rural logistics in the near future.

Fresh farm produce must be kept within a specified temperature and humidity range to ensure freshness, tastiness, and safety. Coupled with mobile communications, sensors in refrigerated vehicles can send temperature and humidity data, as well as integrity data, to supply chain stakeholders anytime and anywhere. For example, the shipper, receiver, logistics operator, and relevant government agency can be notified of any breach of a sealed vehicle door during transit.

GPS technology facilitates the tracking and tracing of cargo and transport assets, and can be used to control the movement of vehicles along certain designated routes (e.g., for highvalue cargo security, or for facilitating customs monitoring). GPS tracking has become very popular in the logistics industry. The technology makes it possible for logistics systems to see the locations of drivers and cargoes, thus providing useful information to a company's partners and customers.

GIS is a new, but promising, application in logistics management. GIS platforms can assist in vehicle monitoring, maintenance management, vehicle scheduling, performance evaluation, order management, and other functions that make logistics management more efficient.

Logistics information systems that integrate smart-sensor, GPS, and GIS technologies can provide real-time spatial-information-analysis capabilities regarding cargoes, trucks, trains, ships, and planes. The integration of these technologies can make the circulation of agricultural commodities much more efficient. For this reason, it will become an indispensable part of the PRC's rural logistics development.

Real-time warehouse monitoring and data transmission based on the internet of things (loT) is much needed these days, as it is very important for food preservation. When goods are in transit, in addition to accurate ratings of inventory, temperature and humidity controls are very important. Cold-chain shipments use temperature and humidity sensors extensively, with a panel inside each vehicle to monitor the temperature and humidity in real time.

The use of GPS technology in the logistics industry enables operators to understand the status of their goods at any time, including cargo vehicle locations, brands names, the quantity of goods, and other information. This capability can improve the effectiveness of monitoring, reduce the empty-load rate, and thus reduce operational costs for logistics companies. On the other hand, when unexpected situations occur during the actual transportation process, the GPS system can soon inform the dispatching center, enabling it to take appropriate actions as quickly as possible to retrieve cargo and/or reduce any losses. In addition, the GPS network can cover thousands of vehicles at the same time, with a tracking area encompassing the entire country.

In the logistics industry, GIS is used mainly for vehicle management, as part of the process of transportation and distribution. GIS can improve the functions of route selection, warehouse positioning, warehouse capacity setting, strategy selection, and vehicle scheduling, in order to achieve effective management and decision making. 
Several logistics companies use GIS for vehicle monitoring, vehicle maintenance, vehicle scheduling, performance evaluation, bill management, and other functions, benefiting from effective regulatory techniques that greatly improve management efficiency.

\section{H. Applications of Modern Information Technologies to Farming and Logistics}

In traditional agriculture, farmers rely on their experience and intuition to decide the amount of water, fertilizer, pesticides, and herbicides to apply. Nowadays, sensor, GPS, and GIS technologies offer accurate data-based, real-time assistance to facilitate these decisions. This capability is already built into a lot of modern farm equipment to enhance crop yields. Farmers only need to press a few buttons and make a choice, and the machine will do the rest.

The agricultural "internet of things" is being used in greenhouse control systems. Relying on temperature sensors, humidity sensors, $\mathrm{PH}$ sensors, light sensors, and carbon dioxide sensors, farm staff can monitor and control multiple greenhouses by using the web via smartphones or computers. Over time, as farms in the PRC grow in scale, there will be more applications available for their use.

\section{Outlook}

Although the current development of rural e-commerce is still in the initial stage, with the expansion of the internet connectivity and the wide use of mobile phones, there will be an additional 200 million online shoppers in 2020 and it is expected that the e-commerce market will reach a transaction value of up to CNY40 trillion by 2020. The rural e-commerce is believed to further grow to a transaction value of CNY5 trillion-CNY7 trillion in the same time. ${ }^{15}$ Growth is expected to remain strong in major, more mature product categories including clothing and consumer electronics. The biggest opportunities for the expansion of online sales are foreseen for Fast Moving Consumer Goods product categories, such as groceries, personal care, packaged foods, and everyday items. First signs of cross-border activities in e-commerce by farmers in western regions raise expectations for further development in that field and the development of automation and virtual reality, creating "experience" shops rather than offline retail and then serve customers via the online market will further push the expansion of e-commerce.

15 Government of the People's Republic of China, Ministry of Commerce. 2017. Online Shopping Continues to Boom in Rural China. Beijing. 


\title{
IV. INTERNATIONAL EXPERIENCES IN RURAL LOGISTICS DEVELOPMENT
}

\begin{abstract}
- he experiences of Germany, Japan, and the United States (US) with agricultural value chains and rural logistics development (both successes and failures) have been perused for any lessons that could be applied in the PRC. All three countries are deemed global leaders in supply chain management and logistics. Japan is a pioneer in lean supply chains-applying Toyota's lean manufacturing principles to logistics system design and execution. Transport operators in the US manage their operations using sound supply-chain management principles-not just reducing transit time, but also the variability of transit time; improving cargo visibility in the network; and collaborating with various stakeholders to drive efficiency and reliability. Germany has perfected the "freight village" concept for integrated logistics park development (often linked to seaports, but now also used to create inland ports) by creating a high-performance logistics ecosystem consisting of complementary enterprises to provide "one-stop" comprehensive logistics services.
\end{abstract}

The PRC is a high-middle-income country on the path to becoming a developed country. Unlike Germany, Japan, and the US, it still has a very large rural population, and agriculture remains a substantial contributor to its gross domestic product (GDP).

Table 2 shows that the PRC's rural residents constitute $44 \%$ of the total population, a proportion that is almost seven times higher than that of Japan's rural population (6.5\%). Moreover, the PRC's agricultural value added is equivalent to $9.17 \%$ of the GDP, which is over 13 times higher than Germany's, which is $0.68 \%$.

Table 2: Profiles of the People's Republic of China, the United States, Germany, and Japan, 2014

\begin{tabular}{|l|l|r|r|r|r|}
\multicolumn{1}{c|}{ Item } & \multicolumn{1}{c|}{ Unit } & PRC & \multicolumn{1}{c|}{ US } & Germany & Japan \\
\hline Surface area & 'O00 square kilometer & 9,598 & 9,632 & 357 & 378 \\
\hline Population & millions & 1,364 & 319 & 81 & 127 \\
\hline GDP & \$trillion & & 17 & 4.6 \\
\hline GDP growth & annual rate & 7.36 & 17.4 & 3.8 & 4.6 \\
\hline Agricultural value added & \% of GDP & 9.17 & 1.30 & 0.68 & 1.28 \\
\hline Rural population & \% & 44.4 & 18.4 & 24.7 & 6.5 \\
\hline
\end{tabular}

GDP = gross domestic product, PRC = People's Republic of China, US = United States.

a In this table, "\$” refers to US dollars.

Sources: Government of the United States, Central Intelligence Agency. The World Factbook. https://www.cia.gov/library/publications/the-world-factbook/; The World Bank. 2014. 


\section{A. The World Bank's Logistics Performance Index}

Germany, Japan, and the US are all ranked among the top 10 countries in the 2014 World Bank's Logistics Performance Index (LPI). They are recognized for their high achievements in the categories of "Infrastructure," "Logistics quality and competence," and "Tracking and tracing." 16

The PRC's logistics performance, as measured by World Bank's LPI, has improved substantially since the start of the "reform and opening up," 35 years ago. But its LPI scores for "Logistics quality and competence" and "Timeliness" are much lower than its composite score, indicating two potential areas for improvement in the future (see Table 3).

Table 3: Country Rankings in the World Bank's Logistics Performance Index, 2014

\begin{tabular}{|c|c|c|c|c|}
\hline & PRC & US & Germany & Japan \\
\hline \multicolumn{5}{|c|}{ Logistics Performance Index } \\
\hline Rank & 28 & 9 & 1 & 10 \\
\hline Score & 3.53 & 3.92 & 4.12 & 3.91 \\
\hline \multicolumn{5}{|c|}{ Customs } \\
\hline Rank & 38 & 16 & 2 & 14 \\
\hline Score & 3.16 & 3.73 & 4.10 & 3.78 \\
\hline \multicolumn{5}{|c|}{ Infrastructure } \\
\hline Rank & 23 & 5 & 1 & 7 \\
\hline Score & 3.63 & 4.18 & 4.32 & 4.16 \\
\hline \multicolumn{5}{|c|}{ International Shipments } \\
\hline Rank & 22 & 26 & 4 & 19 \\
\hline Score & 3.50 & 3.45 & 3.74 & 3.52 \\
\hline \multicolumn{5}{|c|}{ Logistics Quality and Competence } \\
\hline Rank & 35 & 7 & 3 & 11 \\
\hline Score & 3.46 & 3.97 & 4.12 & 3.93 \\
\hline \multicolumn{5}{|c|}{ Tracking and Tracing } \\
\hline Rank & 29 & 2 & 1 & 9 \\
\hline Score & 3.50 & 4.14 & 4.17 & 3.95 \\
\hline \multicolumn{5}{|c|}{ Timeliness } \\
\hline Rank & 36 & 14 & 4 & 10 \\
\hline Score & 3.87 & 4.14 & 4.36 & 4.24 \\
\hline
\end{tabular}

PRC $=$ People's Republic of China, US = United States

Notes: The Logistics Performance Index reflects assessments of a country's logistics based on the efficiency of the customs clearance process, quality of trade- and transport-related infrastructure, ease of arranging competitively priced shipments, quality of logistics services, ability to track and trace consignments, and frequency with which shipments reach the consignee within the scheduled time. The index ranges from 1 to 5 , with a higher score representing better performance.

Source: J.F. Arvis et al. 2014. Connecting to Compete 2014: Trade Logistics in the Global Economy-The Logistics Performance Index and its Indicators. Washington, DC: World Bank. https://openknowledge.worldbank.org/ handle/10986/20399

16 World Bank. Logistics Performance Index 2014. http://lpi.worldbank.org/ 


\section{B. Comparing Integrated Logistics Parks}

Considering that integrated logistics park development is a PRC government priority, Table 4 below provides a comparison of integrated logistics parks in Germany, Japan, and the US.

Table 4: A Comparison of the Planning, Design, Financing, Construction, and Operation of Integrated Logistics Parks in the United States, Germany, and Japan

\begin{tabular}{|c|c|c|c|}
\hline Item & United States & Germany & Japan \\
\hline Planning & $\begin{array}{l}\text { No comprehensive federal } \\
\text { government master plan } \\
\text { Planning at the regional level } \\
\text { to meet regional development } \\
\text { objectives and market needs } \\
\text { Private-public coordination } \\
\text { and provider-user } \\
\text { coordination (e.g., } \\
\text { CenterPoint Intermodal } \\
\text { Center, Chicago) }\end{array}$ & $\begin{array}{l}\text { Master plan } \\
\text { Coordinated by municipal } \\
\text { and state governments } \\
\text { Infrastructure development } \\
\text { by the federal government }\end{array}$ & $\begin{array}{l}\text { Government-driven } \\
\text { Prime focus on rationalizing } \\
\text { urban logistics } \\
\text { Development planning of } \\
\text { logistics parks framed by the } \\
\text { government; choices of sites } \\
\text { on the edge of cities, and on } \\
\text { circumferential and radial } \\
\text { expressways, made by the } \\
\text { government }\end{array}$ \\
\hline Design & $\begin{array}{l}\text { Market-driven } \\
\text { Toward integration with } \\
\text { multimodal network }\end{array}$ & $\begin{array}{l}\text { Supervisory board } \\
\text { Toward integration with } \\
\text { multimodal network }\end{array}$ & $\begin{array}{l}\text { Government-driven } \\
\text { Toward integration with } \\
\text { multimodal network }\end{array}$ \\
\hline Finance & $\begin{array}{l}\text { Privately funded through a } \\
\text { government subsidy, loan } \\
\text { or loan guarantee, equity } \\
\text { plus bank loans, and sales of } \\
\text { securitized instruments }\end{array}$ & $\begin{array}{l}\text { Government financing and } \\
\text { support if project is too } \\
\text { complex and expensive for } \\
\text { private investment }\end{array}$ & $\begin{array}{l}\text { Government-expedited } \\
\text { investment under the } \\
\text { "Administration Outline for } \\
\text { Comprehensive Logistics," } \\
\text { introduced in } 1997 \\
\text { Support for logistics } \\
\text { infrastructure (railways, roads, } \\
\text { airports, ports, and bases) }\end{array}$ \\
\hline Construction & $\begin{array}{l}\text { Market-driven, based on } \\
\text { customer needs }\end{array}$ & $\begin{array}{l}\text { Based on customer needs } \\
\text { and economic development } \\
\text { objectives }\end{array}$ & $\begin{array}{l}\text { Low-interest loans for } \\
\text { construction provided by } \\
\text { the government because } \\
\text { improvements in urban } \\
\text { transport and city functions } \\
\text { offer a low return on investment, } \\
\text { but a high return to society }\end{array}$ \\
\hline Operation & $\begin{array}{l}\text { Operation frequently } \\
\text { separated from ownership } \\
\text { Value-added services }\end{array}$ & $\begin{array}{l}\text { By supervisory board, } \\
\text { frequently with tenant } \\
\text { participation } \\
\text { Value-added services }\end{array}$ & $\begin{array}{l}\text { Advanced e-commerce } \\
\text { capability } \\
\text { Value-added services }\end{array}$ \\
\hline
\end{tabular}

Source: Asian Development Bank. 


\section{The United States Experience}

\section{Agricultural Value Chains in the United States}

The US agricultural value chains are shorter, simpler, and much less fragmented than those in many countries. They are more horizontally integrated, with larger farms, powerful co-ops, and trade associations. Vertical integration is also prevalent, with both forward integration (growers owning packers) and backward integration (processors owning farms) in many sectors (Figure 6). There is much less intermediation than in the PRC. And there is virtually no origin wholesale market because farms sell directly to supermarkets, food-service companies, fast-food chains, and destination wholesale markets.

Figure 6: A Typical Farm-Produce Value Chain in the United States

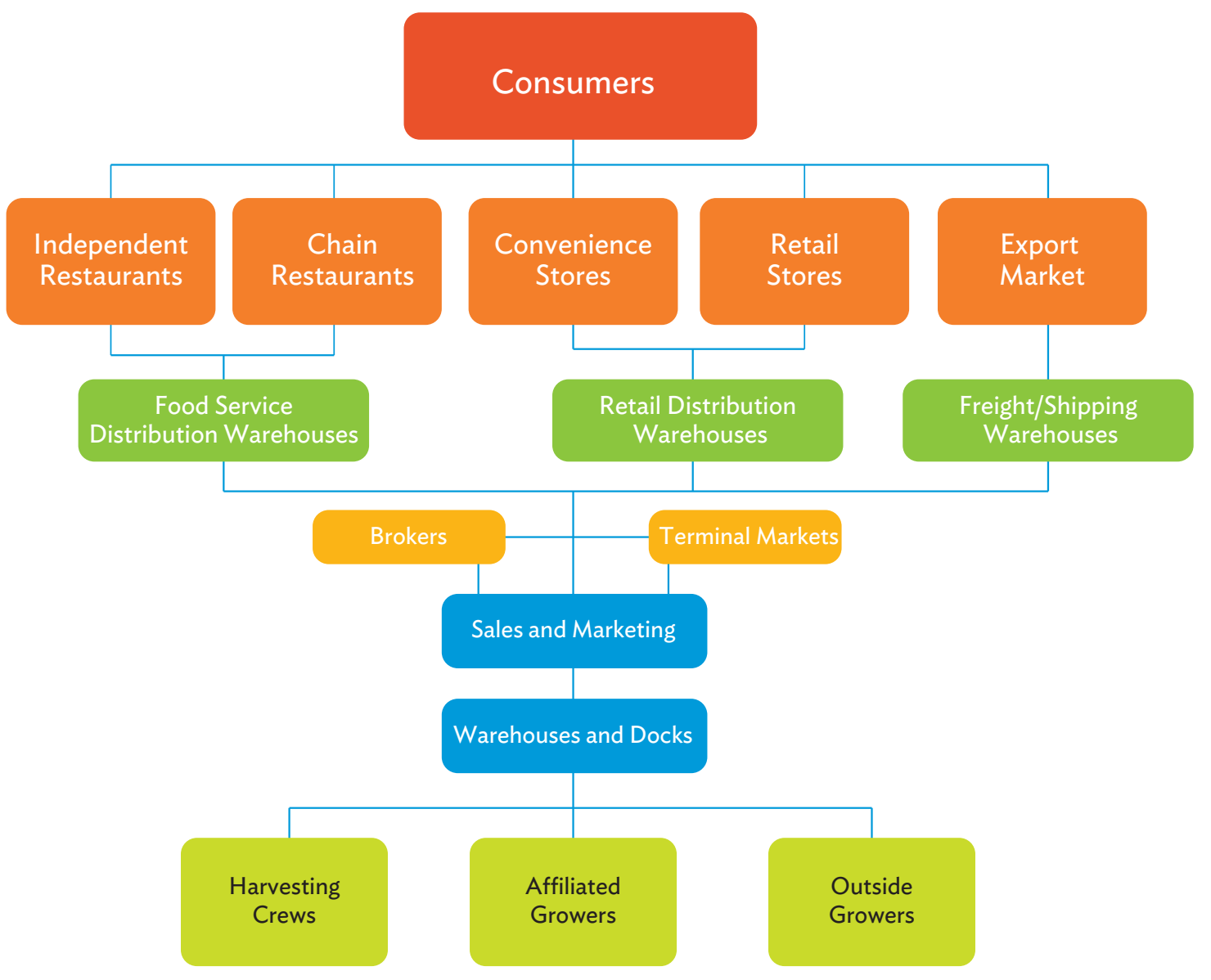

Source: Produce Marketing Association. http://www.pma.com/ 
Exporting products globally, the $\$ 130$ billion per year fresh-produce industry is dominated by large growers and shippers, with diverse product selections and multiple supply points across broad geographic areas. The US has a high industry concentration, which is facilitated by an efficient market for buying and selling farmland, as well as ready access to financing.

Competition among growers is intense due to low competitive barriers that cannot restrict new entrants and to strong international competition (e.g., Mexico, with its much lower land and labor costs, as well as higher-quality soil). Consolidation among buyers (supermarkets, food-service companies) increases pricing pressures on growers and shippers, and drives out small players. Large buyers clamor for a streamlining of the supply chain to eliminate nonvalue-adding costs and to improve food safety. Such actions help shorten the US agricultural value chain.

To protect farmers, the Government of the United States, under the Agricultural Marketing Agreement Act of 1937, permits cartel-like practices that are illegal in other industries. These include

(i) restricting supply;

(ii) setting standards for size, shape, color, and quality; and

(iii) permitting information sharing and price fixing.

Relationships between produce buyers and sellers are generally long term and stable, with reputation and brand equity critical to the success of growers and shippers. Reputation in the industry is developed over years of fair, ethical trade practices; the honoring of commitments (which are frequently verbal); and doing what is right for all parties. Brand equity is built through product and service quality, consistency, and value.

The fresh produce industry in the US is highly industrialized. Farming, packing, and shipping operations are heavily mechanized and frequently automated. Produce is engineered for planting and harvesting efficiency, product uniformity, and yield, as well as for suitability for mechanized processing. When automation is not feasible, growers rely heavily on cheap labor. Many farm workers are undocumented migrants from Mexico and other Latin American countries who go from farm to farm to follow seasonal crops.

Farmers often use large amounts of hazardous fungicides, herbicides, and pesticides; and they apply excessive amounts of chemical fertilizers to increase their yields.

Large, modern facilities are used to clean, wash, chill, preserve, and pack produce. These temperature-controlled facilities are centrally located near farms, and they can be owned and operated by farm co-ops or large growers. They serve one or more growers during the same season or several growers over different seasons, and can be used for packing one type of produce (e.g., just tomatoes) or multiple types of compatible produce (e.g., peaches, nectarines, plums).

Prior to shipping, packed produce is stored in modern cold-storage facilities that have multiple temperature compartments. Some cold storage can provide an inert gas atmosphere to extend freshness. 
To boost profit margins, sellers utilize consumer-friendly packaging and introduce valueadded products (e.g., washed, precut vegetables) to be sold at higher price points.

\section{The United States Logistics System}

The US has a highly developed logistics network that links producers and consumers through multiple transportation modes. Its highly integrated system provides end-to-end logistics solutions that ensure coordinated cargo movements through each link in the supply chainfrom origin to end user.

The US is a recognized global leader in the creation of new logistics service categories and in pushing the envelope with IT applications to supply chain management. It is prolific in generating fresh, creative business models, with many of them becoming mainstream globally. The US is the leader in rail freight transport, and has pioneered many multimodal logistics innovations.

In 2015 , the total US logistics expenditure was $\$ 1.41$ trillion, representing $7.85 \%$ of the GDP. The llogistics cost-GDP ratio is among the lowest in the world, and half of the PRC ratio (Figure 7).

Figure 7: Business Logistics Costs in the United States as a Percentage of Nominal Gross Domestic Product, 2006-2015

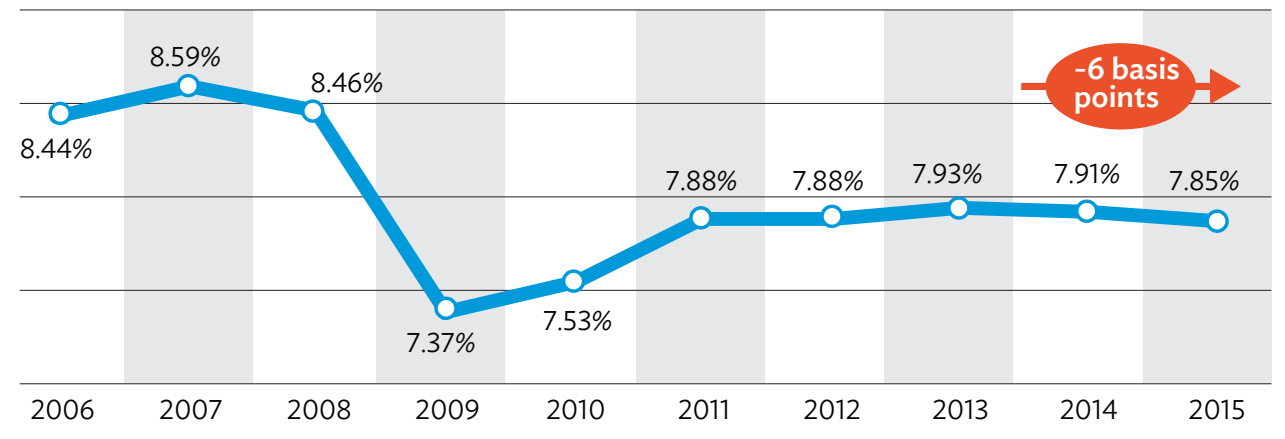

Source: A.T. Kearney. 2016. Logistics in Transition: New Drivers at the Wheel. The 27th Annual State of Logistics Report. Lombard, IL: Council of Supply Chain Management Professionals.

\section{The Structure of the American Logistics Industry}

The American logistics industry is mature, with a low single-digit overall growth rate that tracks the GDP growth rate. Logistics operators scale through organic growth, as well as through mergers and acquisitions. There is a large variety of asset-based transport and logistics service providers, including

(i) truckload, dry (local, national, regional, interregional);

(ii) truckload, temperature-controlled (local, national, regional, interregional); 
(iii) less-than-truckload (local, national, regional, interregional);

(iv) parcel (local, national, regional, interregional);

(v) rail (two western, two eastern, many short lines);

(vi) distribution center (transload and crossdock);

(vii) warehouse; and

(viii) the postal service.

There is also a large variety of non-asset-based transport and logistics service providers, including

(i) third-party logistics providers,

(ii) fourth-party logistics providers,

(iii) truck brokers,

(iv) freight forwarders,

(v) intermodal marketing companies,

(vi) freight payment services,

(vii) freight claim services,

(viii) reverse logistics providers, and

(ix) supply chain IT services.

Logistics industry concentration in the US is much higher than in the PRC, as the industry is dominated by large operators with significant economies of scale, the benefits of the network economy, and access to financing. For example, the average US fleet size is 3,000 trucks, compared with 1.4 trucks in the PRC.

Easy access to various financing schemes fosters growth and innovation in the logistics sector. There is a wide variety of financing sources in addition to banks, including leasing companies, private equity funds, pension funds, and venture capital investors. The US also has a highly liquid and efficient stock market and bond market, which logistics companies can tap. Further, various government programs support the logistics industry at the national, state, and local levels. Competition in the transport and logistics industries is intense and generally based on the following factors:

(i) price,

(ii) speed of delivery, 
(iii) reliability of service,

(iv) ability to provide capacity during peak demand periods,

(v) resiliency and robustness of the network,

(vi) range of service capabilities,

(vii) geographic coverage,

(viii) innovation and creativity (especially in problem solving),

(ix) staff competency, and

(x) customer relations.

Trust and reputation are critical in selecting transport and logistics operators. Unsafe and financially weak operators are quickly abandoned by shippers.

Except in the package express market, which is dominated by the UPS-FedEx duopoly, transport and logistics operators have limited pricing power. Pricing depends on capacity, service differentiation, and customer relations, with a long-term trend toward stable contract rates between large carriers and large shippers (i.e., the customers with the cargo to move).

\section{Logistics and Transport Industry Management in the United States}

Logistics operators in the US focus on their core businesses, building durable enterprises. Key performance indicators are carefully monitored and metrics are used for continuous improvement. To protect core competencies, employee capacity development is embraced.

Innovation is an important competitive tool as well, with the best companies constantly searching for new technological applications to advance their businesses (e.g., FedEx's migration to cloud computing). And smart, IT-centric startups are finding new ways to revolutionize the industry. Recent applications of information and communication technology include

(i) big data;

(ii) internet of things;

(iii) cloud computing;

(iv) analytics software for "descriptive," "predictive," and "prescriptive" applications;

(v) revenue management, spot pricing software; and

(vi) crowdsourcing apps.

Moreover, a range of modern hardware is being deployed to make operations more efficient, such as temperature sensors, safety enhancement tools, and digital driver-activity recorders (to minimize idling, sudden stops, and excessive acceleration). Cutting-edge technologies such as self-driving trucks with forward-looking stereoscopic cameras and radar sensors, as 
well as cargo delivery drones, are actively being tested (e.g., Otto, a startup producing selfdriving trucks). To facilitate supply-chain data sharing, industry committees set stringent supply-chain data standards and electronic data interchange standards.

The transport industry has clear, well-designed standards. Vehicle dimensions vary a lot less compared with those in the PRC. Illegal vehicle modification, a common practice in the PRC, is rare in the US. Material handling is highly automated and mechanized. The variety of pallet sizes is much smaller than in the PRC, and pallet dimensions are harmonized with interior trailer dimensions to enhance cube utilization.

Trucking companies in the US are lightly regulated. The Department of Transportation focuses mainly on safety, liability, cargo insurance, and regulatory compliance. Freight forwarders are also lightly regulated, with a focus mainly on ensuring adequate insurance coverage for cargoes. Truck brokers are very lightly regulated as well. The Department of Transportation only requires brokers to obtain a surety bond to ensure that carriers are paid. Logistics companies, intermodal marketing companies, and warehouse and distribution center operators are not regulated by the Department of Transportation.

However, in contrast to the PRC, the enforcement of regulations is strong in the US. Overloaded trucks are shut down immediately and often subjected to further inspections to find other infractions. Accidents caused by overloading and driver fatigue can bring heavy penalties, as well as civil and criminal lawsuits.

The Federal Motor Carrier Safety Administration, under the Department of Transportation, publishes its safety ratings of carriers on its information portal, along with a list of each carrier's safety violations and insurance coverage. This shines a bright spotlight on poor operators, and encourages them to take immediate remedial actions. Publicly accessible safety ratings also highlight shippers that hire unsafe carriers, removing the use of ignorance as a defense. A poor safety rating will cause a carrier to go out of business, thus ensuring that a bad player is quickly driven from the market.

Railroads and highway carriers are represented by strong trade associations. In contrast to the PRC, US trade associations are not part of government or under government control. They advocate on behalf of their members in their efforts to gain favorable government treatment and improved relations with the public. The federal government refrains from private sector activities (e.g., operating freight exchanges), only intervening during periods of emergency. However, the government does fund research and support projects with desirable social outcomes (e.g., the United States Environmental Protection Agency's SmartWay program).

\section{Rural Logistics in the United States}

The infrastructure in rural areas of the US is generally good, with adequate rail and road network coverage. The interconnectivity between modes (rail and road) and among networks (rural, interstate, national) is well-developed.

A substantial number of modern logistics facilities are being built in rural areas to take advantage of lower land prices and cheaper labor costs. Local government incentives have also attracted logistics facilities to rural areas. As in the PRC, it is very difficult to earn a profit from providing rural logistics services. Key reasons are as follows: 
(i) Traffic density is low.

(ii) Pickup and delivery points are far from each other.

(iii) Outbound agricultural products and inbound consumer products and farm inputs are generally handled via different logistics chains.

(iv) Due to their different characteristics, agricultural products, consumer products, and farm inputs are not transported in the same vehicles (e.g., fresh produce cannot be placed in trucks carrying poisonous insecticides and herbicides).

(v) Agricultural products are seasonal, cyclical, bulky, and perishable, and they lack size uniformity.

(vi) Shipping times may be affected by weather conditions such as rain and sudden changes in temperature.

Consequently, rural logistics is not a desirable business for US transport and logistics operators. However, large operators do offer decent rural coverage. For example, UPS, FedEx, and virtually all the national trucking firms serve remote rural areas. The reasons why they provide rural coverage are as follows:

(i) Profitable urban cargo shipments can be used to subsidize unprofitable rural cargo shipments.

(ii) Large shippers demand that carriers serve all points in a given region, and that they accept all cargo tendered (i.e., no cherry-picking the most profitable destinations).

(iii) The higher rates charged for rural routes partly compensate for the high cost of rural service.

In addition, commercial carriers can use the US Postal Service for remote locations that do not fit into their networks. By law, the US Postal Service must serve the entire country, including loss-making rural locations. The Rural Post Roads Act of 1916 provided federal funding to the states for the construction of rural post roads. To save on delivery costs, rural mailboxes are clustered at road junctions. And for extremely remote locations, the US Postal Service provides free mailboxes at the nearest post office.

\section{The German Experience}

\section{The Agricultural Value Chain in Germany}

The agriculture sector accounts for a very small share of the German economy. The number of farms has been decreasing steadily since the late 1960s. Most of the farms are familyowned. For many of them, farming is not the owners' full-time occupation. Attracted by better incomes, many farmers have left agriculture for the industrial and service sectors.

On the flat terrain of northern Germany, potatoes, cabbages, sugar beets, and grain are the main agricultural products. In the hillier parts of the country, farmers grow vegetables and fruit, and produce milk. Farm productivity is high due to extensive mechanization. 
A significant number of farm co-ops in the former East Germany (now Germany) remained after the reunification, and now play an important role in the agriculture sector.

However, most of Germany's food is imported. As a key member of the European Union (EU), it is subject to agricultural laws and regulations crafted in Brussels to provide high incomes for the farmers while keeping market prices low enough to avoid consumer protests. EU agricultural reforms in 1992 cut market price supports, replacing artificial prices with government subsidies, and put strict controls on output volume. The Government of Germany and the state governments have provided financial assistance for agricultural development, land consolidation, village renewal, and the construction of rural roads. Special funds have been made available for economically challenged areas where agriculture is an important economic and social factor. The federal government encourages good agricultural practices, requiring that the application of fertilizers and plant-protection chemicals not to exceed mandated maximum levels, and offers financial incentives to farmers who use environmentally friendly agricultural methods.

Germany is the world's second-largest market for organic produce after the US. Its citizens support sustainable farming that will not harm the environment, and many are willing to pay higher prices for organic produce.

\section{The German Logistics System}

Germany has the fourth-largest economy in the world. Located in the heart of Europe, and surrounded by nine countries, it has easy access to almost 250 million consumers within a 500 -kilometer radius. It is one of the most logistically advanced countries in the world, with excellent infrastructure, innovative supply-chain technology, and a strong logistics industry. It is a hub for all trans-European transport routes. As the gateway country to Europe, Germany provides the most attractive location for goods distribution, as well as the largest logistics market in the EU. In fact, Germany is home to numerous global logistics service providers.

The foundation of a successful logistics industry is a well-developed infrastructure. With over 650,000 kilometers of roads, 42,000 kilometers of rail, 36 ports, and 27 airports, Germany offers a variety of efficient transport networks covering all modes. As there are 2.56 million trucks, most German freight is transported by road. According to the German Federal Association for Freight Transport, Logistics and Waste Management, in 2015 the roads accounted for about $77 \%$ of total transport volume, carrying 3.5 billion tons of cargo. Rail was the second-largest freight transport segment in Germany, but only carried a total of 365 million tons of goods, a small fraction of the amount carried by trucks.

Germany is not just advanced with regard to hard logistics infrastructure; its logistics technology is also highly developed. The German federal and state governments strongly promote the logistics industry, not just in research and development, but also in sales and marketing. Logistics Alliance Germany is an example of a public-private partnership between the Federal Ministry of Transport and Digital Infrastructure and the German logistics industry.

Germany's excellent road network enables reliable service to rural areas. Its carriers utilize safe, clean, modern vehicles for pickups and deliveries. In addition, Germany has extensive and well-developed rail and inland waterway networks serving rural areas, so rural logistics coverage is relatively good. 


\section{E. The Japanese Experience}

Japan is a thought leader in supply chain management and excels in logistics applications. The Government of Japan has applied Toyota's lean manufacturing principles to promote lean supply chains, thus greatly influencing logistics system design, execution, and quality standards. The Japanese logistics industry is shaped by very high requirements, set by its customers, that entail lean supply chain principles. This includes high-frequency schedules, high-performance standards (fast transit times, low transit-time variability, and a low incidence of loss and damage), and top-notch customer service.

With product lines long on diversification and short on time to market, Japanese companies emphasize short lead times for reaching consumers. This approach not only enables adjustments to changing customer preferences, but also reduces inventory costs.

\section{The Agricultural Value Chain in Japan}

Farming exists in every part of Japan. The northern island of Hokkaido is the most important agricultural region, accounting for $10 \%$ of national production. Japan has a long agricultural history. Before its rapid urbanization and industrialization, which started in the 1950s, Japan had a sizable rural population, with half of the country's households engaged in farming. Today, due to rural depopulation and international competition, a substantial percentage of the plots have been abandoned and agricultural output has been much curtailed.

The Japanese culture supports many forms of cooperation. Consequently, "marketing co-ops" and "purchasing co-ops" are prevalent in the economy. Until recently, almost every village had a co-op, with farmers, fishers, and forest owners as members. While the total number of co-ops has been decreasing, there were still almost 12,000 community-based (voluntary) farm cooperatives registered in 2013. The Japan Agriculture Association, the national network of local agricultural cooperatives, is one of Japan's most powerful lobbies; it works to secure strong government support for farmers, and campaigns to maintain farm subsidies and high tariffs on imported agricultural goods.

Due to Japan's mountainous terrain and limited amount of arable land, the farms are small, with an average size of 1.5 hectares. Most farming areas consist of a mosaic of plots, with the plots belonging to one farmer dispersed among those belonging to other farmers. Out of Japan's 1.5 million farmers, only 420,000 are engaged in farming full-time. The part-time farmers are generally old, with few offspring following their path. They tend not to invest, as farming is not their main source of income. Consequently, farming is not as mechanized or automated as in other developed countries.

However, small farms are also prevalent due to the consumers' preference for quality goods that are locally produced, and to their willingness to pay higher prices to support small farms. Concern about food safety and security, as well as a sense of social responsibility and the desire to preserve the Japanese culture and traditions, also contribute to the survival of small farms.

\section{The Japanese Logistics System}

The Japanese logistics system faces serious structural challenges. Domestic transportation costs are significantly higher than in other developed countries. The Japanese economy has 
been stagnating since the 1990s, and the volumes of imports and exports have dropped, putting a strain on the country's transportation and logistics industry.

To divert freight from the country's congested highways, lessen its energy dependency, and reduce pollution, the government promotes road-rail, coastal rail-water, and road-water intermodal movements. It plays a role in ensuring good coordination among the various transport modes. The government also supports the trucking industry through a system of stable tariff rates to provide an adequate margin for investing in new equipment, such as low-emission vehicles.

The government adopted a comprehensive logistics policy in 2005 aimed at strengthening its logistics system. This included superport development to expand the collection and distribution areas served by the ports. These mega-ports benefit from economies of scale, use expensive high-tech tools, and have expanded capacity for handling intermodal shipments.

Japanese manufacturers prefer to work with domestic logistics companies to supply their overseas factories. The government does not impose logistics regulations other than those concerning vehicle safety. As safety regulation is stringent and enforcement is strong, logistics operators behave responsibly.

Japan is currently trending toward consumer-driven logistics, using IT to manage customer orders and to make the supply chain more effective. The earthquake and tsunami of 2011 also brought forth changes in logistics thinking. Companies that had not diversified their logistics networks suffered from prolonged interruptions, resulting in delays in the transport of goods. The disaster demonstrated the importance of flexible logistics solutions when it comes to supporting modern supply chains.

\section{Rural Logistics in Japan}

The populations of some rural towns have dropped by $25 \%$ or more. Rural communities are losing public transportation due to the lack of passengers. Stores, clinics, and other service providers have closed due to insufficient demand. This situation puts a strain on logistics service providers.

Large logistics operators such as Nippon Express, Kintetsu, and Yamato provide rural coverage, and are fully aware of the unprofitability of transporting rural cargo. However, they are concerned about public criticism, and want to maintain a good corporate image, so they continue to serve rural areas as a sign of their social responsibility. Japan Post also serves the entire country, with rural post offices also serving as banks and insurance companies. Even though these rural postal offices are unprofitable, Japan Post maintains them as a public service.

In general, large shipments are handled by logistics operators, while small shipments are handled by Japan Post. Even though logistics operators compete with Japan Post, they also cooperate in getting shipments to their destinations.

The country has a very good cold storage network and excellent air, truck, and rail infrastructure. It also has top-notch transport and logistics operators to speed farm products to large cities such as Tokyo and Osaka, and to smaller destinations. The expansion of the internet, mobile communications, and e-commerce to rural areas is helping small farmers sell their products directly to urban consumers. E-commerce has also replaced the stores 
that have closed down in rural areas, so Japanese villagers can again source the products they need. Modern information and communication technology has enabled the deployment of demand-responsive transportation (e.g., on-demand bus service) for thinly populated villages where a scheduled bus service would not be economical.

Rural delivery rates are set by the carriers, using distance as a guide. Surcharges are levied for hard-to-reach areas such as small islands and remote mountain locales. The government provides subsidies and low-interest loans to rural co-ops for logistics productivity improvements, such as the construction of consolidation and distribution centers for farm products and rural cargoes. 


\section{RECOMMENDATIONS FOR IMPROVING RURAL LOGISTICS}

\footnotetext{
- his study has resulted in a set of policy recommendations to help the PRC achieve the following objectives: (i) enhance government support, (ii) strengthen rural logistics infrastructure, (iii) increase the informatization of rural logistics systems, and (iv) cultivate strong rural logistics enterprises. Table 5 presents an overview of all the recommendations, which will be elaborated on further in this chapter.
}

Broadly speaking, the government should focus on what the public sector does best:

(i) create a friendly business environment for rural enterprises;

(ii) formulate well-thought-out policies, laws, and regulations with input from stakeholders;

(iii) foster an open, competitive market in which efficient, reliable, safe, and ethical rural logistics companies perform well, and unscrupulous players are driven out;

(iv) work with stakeholders to develop proper standards and specifications; and

(v) invest in underlying infrastructure.

In an enabling business environment, the private sector would play its role by

(i) generating more efficient, more reliable logistics enterprises that will drive out poor operators;

(ii) adopting new business models, new technologies, and new methods that will disrupt the existing logistics system;

(iii) optimizing business operations and enhancing customer service; and

(iv) allocating capital to geographic areas with a high potential for rural logistics improvement.

As the PRC is still transitioning into a market economy, the government frequently plays an active role in "guiding" the private sector. Therefore, with some of the recommendations aimed at the private sector, there will still be a place for public sector involvement. 
Table 5: Recommendations for Improving Rural Logistics in the People's Republic of China

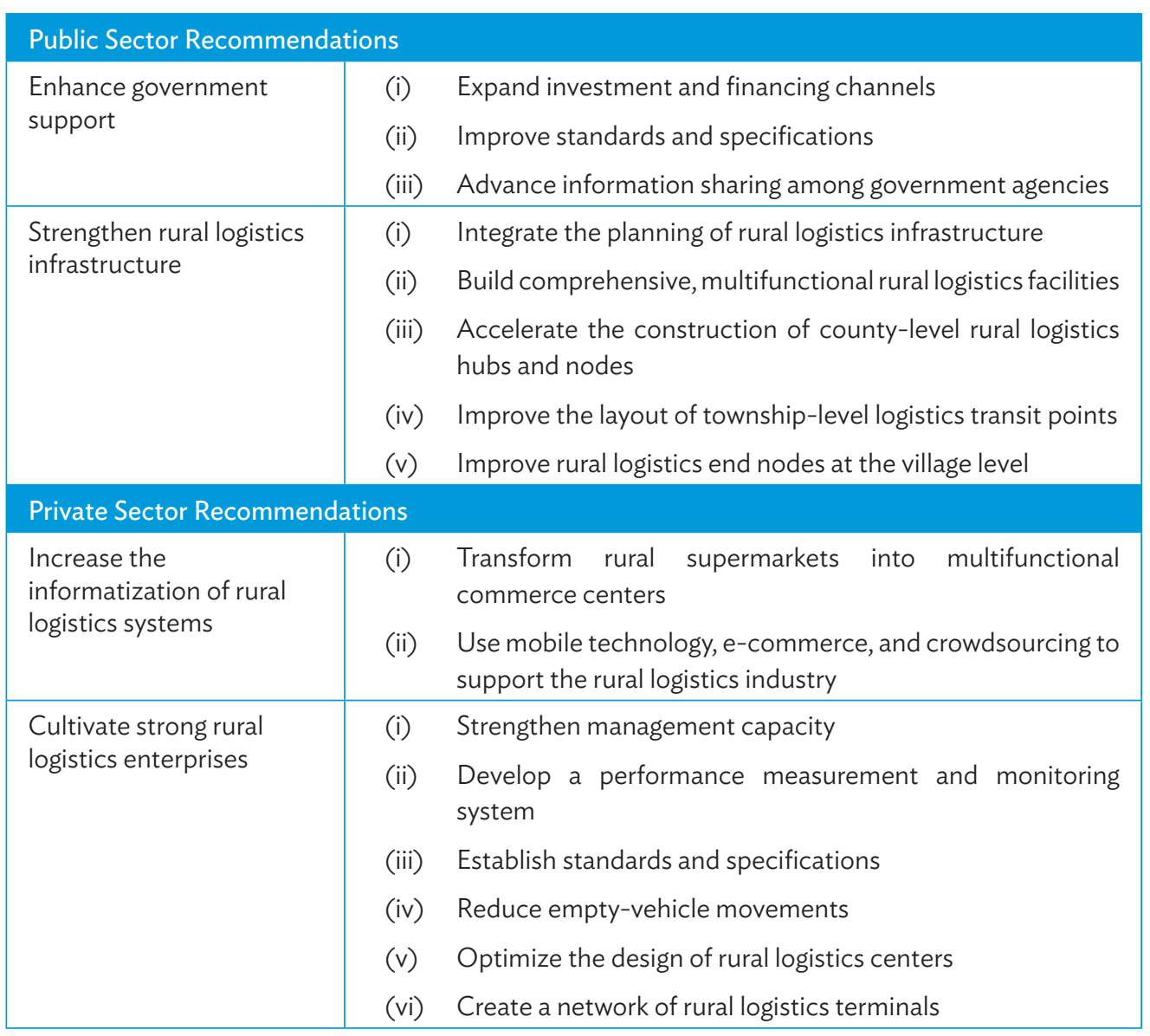

Source: Asian Development Bank.

\section{A. Public Sector Recommendations}

\section{Enhance Government Support}

With the wide variety of institutions and stakeholders involved in rural logistics, special attention should be given to making policy formulation and implementation more effective, and this should involve authorities at national, provincial, and local levels. Government policies concerning transportation, commerce, farm supply, and marketing need to be integrated. During implementation, a leading role should be given to local governments. Government units should coordinate their procedures for addressing key issues and difficulties.

Funding from the national, provincial, and local governments is needed to support the upgrade of rural vehicles and equipment, the construction of a rural logistics publicinformation network, and the promotion of private sector involvement. 


\section{i. Expand Investment and Financing Channels}

This would entail encouraging rural logistics enterprises to raise funds through stock sales, mergers, or acquisitions; and encouraging them to use emerging internet financing modes such as e-banking platforms. The government should also expand investment channels, streamline loan application procedures, and help finance rural logistics enterprises to support their growth.

The development of a credit and trade practice rating system should be expedited, and the system should determine credit ratings for relevant business operators, such as rural logistics enterprises and agricultural product markets.

\section{ii. Improve Standards and Specifications}

The government should expedite the construction of a reliable tracing system to ensure the quality of agricultural inputs and agricultural products.

There should be improved standards and specifications for commodity circulation, information platforms, equipment and technology, and business operations related to agriculture. This would include temperature-recording devices and other instruments to support uninterrupted cold-chain transport and in-transit temperature-monitoring capabilities.

\section{iii. Advance Information Sharing among Government Agencies}

The relevant agencies within the Ministry of Transport, Ministry of Agriculture, the Ministry of Public Security, and the Ministry of Commerce, as well as China Co-op and various local government departments handling rural-logistics issues, should be encouraged to share information on logistics infrastructure, credit and trade practices, safety violations, and rural logistics-service supply and demand-as this will support rural logistics development.

The role of markets should be strengthened, with private enterprises as the main driver in creating logistics information platforms and mobile applications. The government should promote interconnectivity among logistics information platforms and enterprise information systems to effectively link various players in the supply chain. And the government should play a coordinating role in an effort to encourage courier companies, rural transport enterprises, rural bus companies, and the postal service to use the internet to connect with one another and to share resources in order to reduce rural logistics costs.

\section{2 .Strengthen Rural Logistics Infrastructure}

\section{i. Integrate the Planning of Rural Logistics Infrastructure}

There should be improvements in the coordination of rural-logistics-infrastructure planning by the Ministry of Transport, Ministry of Commerce, China Co-op, and the State Post Bureau, especially with regard to infrastructure locations, resource sharing, and co-development. The central government should promote the unified planning of rural logistics in selected provinces, and prefectural or city-level rural logistics planning should be synchronized with provincial development planning. What follows are additional recommendations:

(i) The authorities in charge of developing provincial transport master plans should create rural-logistics implementation plans as soon as possible;

(ii) City and county transport authorities should prepare logistics-system plans and promote the orderly construction of a three-level rural logistics network; 
(iii) Integrated rural logistics planning should be promoted at the local government level. Planning coordination should be strengthened in the interest of achieving effective connections among rural logistics infrastructure, information technology (IT) platforms, and the distribution network. In addition, rural logistics infrastructure planning should be incorporated into urban-rural integration planning; and

(iv) The government should establish professional research institutions and encourage them to come up with plans related to rural logistics development and improvement; they should also prioritize research on the integration of cold chain logistics for key agricultural products.

\section{ii. Build Comprehensive, Multifunctional Rural Logistics Facilities}

The government and the private sector should cooperate in developing logistics parks with comprehensive functions pertaining to agricultural product circulation, processing, storage, transport, and distribution. They should strengthen the linkages between logistics park planning and other planning related to the development of the PRC's agricultural market system. As a complement to the development of the production and sales components of agricultural markets, as specified in the document Planning of National Agricultural Product Market Systems (2015-2020), they should also cooperate in the construction of supporting logistics parks (cargo hubs) with circulation, processing, storage, transport, and distribution functions. And they should strengthen the overall planning and construction of logistics parks (cargo hubs) and postal logistics distribution centers, with the aim of intensively integrating the logistics resources of the transport and postal sectors. Finally, they should strengthen the interconnectivity between existing logistics parks and agricultural production bases, agricultural product wholesale markets and distribution nodes, and agricultural input distribution centers, as well as postal distribution centers, in order to upgrade the effectiveness of rural logistics.

\section{iii. Accelerate the Construction of County-Level Rural Logistics Hubs and Nodes}

The central government and local authorities should work to integrate the rural logistics resources pertaining to transport, commerce, farm supply and marketing, and postal services; develop a rural logistics network based on three levels of nodes (county or district, township, and administrative village); and follow the model of "multiple functions in one node, with resource sharing." With rural logistics centers serving as a base, they should also collocate rural markets, agricultural product collection points, renewable resource recycling centers, and agricultural-input distribution centers. And they should expedite the construction of county-level rural logistics hubs and nodes to centralize the management of rural logistics supply and transport, and to improve the connections with the national trunk logistics networks.

\section{iv. Improve the Layout of Township-Level Logistics Transit Points}

The government should expedite the transformation of township-level rural passenger terminals based on the "three-terminals-in-one" template (passenger terminal, traffic control station, and rural logistics outlet).

It should construct comprehensive rural-transport service stations that would combine the following functions:

(i) passenger transport service,

(ii) traffic control, 
(iii) agricultural inputs warehousing,

(iv) agricultural products warehousing,

(v) consumer goods warehousing and distribution,

(vi) renewable resources recycling, and

(vii) express parcel collection and distribution.

\section{v. Improve Rural Logistics End Nodes at the Village Level}

County and town authorities should promote the use of rural supermarkets, village shops, postal service outlets, farm cooperatives, and China Co-op sales outlets to support the rollout of the following projects:

(i) Building Standardized Farm Shops in $50 \%$ of Villages and $70 \%$ of Towns Nationwide,

(ii) Construction of a New Modern Rural Circulation Network, and

(iii) “Three Rural” Service” Stations.

They should follow the principles of business cooperation and putting customer service first. And they should develop compact rural logistics centers as end nodes, taking advantage of the end nodes' proximity to farmers, their dense and broad coverage of "first kilometer" and "last kilometer" distribution and collection, and the convenience they offer for information dissemination.

\section{B. Private Sector Recommendations}

\section{Increase the informatization of rural logistics systems}

\section{i. Transform Rural Supermarkets into Multifunctional Commerce Centers}

At present, rural supermarkets are generally small and offer few product varieties. This sector is characterized by high fragmentation and low profits, a situation that further hinders their development and limits employment opportunities for the rural labor force.

The business model for small rural supermarkets must be revised to enable stable, long-term development. Due to the remote locations and low levels of informatization in rural areas, villagers lack the conveniences of urban life. Transforming small rural supermarkets into multifunctional commerce and distribution centers would enable them to provide a variety of services to rural residents, such as helping customers order tickets online or purchase goods from e-commerce websites.

Machine learning and big data technology could be used to analyze user behavior and provide recommendations and real-time customer intelligence analysis. In addition, users' consumption data could be mined and analyzed to help rural supermarkets manage inventory and increase sales. 
Mobile communication technology could provide convenient links between rural supermarkets and villagers. For instance, supermarkets would be able to receive or ship parcels or small lots of cargo on a villager's behalf. With their upgraded capabilities, small rural supermarkets would not only enrich the daily lives of villagers and promote employment in rural areas, but also maximize the value they add, leading to higher profits and stable, longterm growth.

\section{ii. Use Mobile Technology, E-Commerce, and Crowdsourcing to Support the Rural Logistics Industry}

Smartphone apps could make it easier for local villagers to deliver parcels or small lots of cargo to other villagers - via farm shops or rural supermarkets. For example, a rural supermarket could publicize the need for a parcel delivery to a list of prescreened, registered villagers who are willing to make deliveries for a fee. This would be an easy way for villagers to earn some extra income, especially if they combine the deliveries with trips they had planned to make into town centers, anyway. Moreover, e-commerce initiatives and a crowdsourcing approach would speed up the delivery and lower the delivery cost for the receiver. Overall, logistics costs and services, as well as sustainability, would improve with this new approach, enabling substantial improvements in rural logistics services.

\section{Cultivate Strong Rural Logistics Enterprises}

\section{i. Strengthen Management Capacity}

Logistics knowledge, combined with basics of IT and online marketing, is a critical element in creating an efficient and reliable rural logistics system. Field studies have revealed a strong need to strengthen the logistics competency of rural transport and logistics operators. This would involve teaching supply-chain, transport, and logistics management in county-level towns, through partnerships with local trade associations and technical institutes.

The introduction of professional certification and the creation of knowledge portals with e-learning capabilities would also enhance logistics capacity development.

\section{ii. Develop a Performance Measurement and Monitoring System}

It is an old adage that one cannot manage what one does not measure. Unless logistics performance is measured, there is no objective way of telling if the results are getting better or worse. The managers of logistics enterprises should thus be encouraged to use performance indicators, and listed here are some useful ones:

(i) operating ratio (i.e., the ratio of operating expense to operating revenue);

(ii) velocity (e.g., cargo movements, asset turns);

(iii) percentages of on-time shipment pickups and deliveries;

(iv) variability of transit times;

(v) percentages of cargo loss and damage;

(vi) percentage of correct carrier freight bills; and

(vii) for transport transactions processed electronically, the percentage of service problems resolved with just one contact. 


\section{iii. Establish Standards and Specifications}

Standards and specifications are essential for the efficient operation of a rural logistics system. In a sense, standards form a common language for the various parties along a supply chain. During the course of a cargo shipment, various transportation modes are used, different instructions received, and diverse regulations applied. For this complex process to function well, proper standards must be created.

Consistent, well-conceived, and universally accepted standards will

(i) improve the efficiency and effectiveness of the logistics system,

(ii) enhance logistics service quality,

(iii) facilitate trade and commerce,

(iv) promote safety and security,

(v) support supply chain sustainability and green logistics initiatives,

(vi) enhance clarity in communications, and

(vii) assist in the exchange of knowledge and sharing of technology.

If standards are not consistent, well-conceived, and universally accepted, the costs and time for logistics transactions will increase. To establish effective logistics standards and specifications, the Ministry of Transportation should form a Standards and Specifications Committee, with members from the National Development and Reform Commission (NDRC), Ministry of Commerce, China Co-op, and China Post, as well as major producers and retailers and key rural logistics operators. The work of this committee should encompass "software," as well as "hardware" areas-for example, business processing and equipment standards, to ensure that trading partners and logistics service providers achieve interoperability and to enable the visibility of goods moving through the supply chain.

The following are areas for which standards and specifications should be considered:

(i) logistics center design and construction;

(ii) engineering and manufacturing of material-handling equipment;

(iii) logistics-center operating and safety standards;

(iv) truck design, including dimension and weight standards;

(v) commercial motor vehicle operating and safety standards;

(vi) product packaging standards;

(vii) trade and transport documentation standards;

(viii) logistics system security standards; and

(ix) data interchange standards. 


\section{iv. Reduce Empty-Vehicle Movements}

Empty truck movements are common in rural areas because inbound and outbound commodity shipments generally move through different transport networks and involve different types of vehicles and handling equipment; also, the available planning and operating information is insufficient for enabling the grouping of cargoes into fewer vehicles. As a result, many empty vehicles entering rural areas are met by many empty vehicles leaving rural areas. The large number of empty-vehicle movements leads to high transportation costs and lessens the availability of vehicles during critical periods such as harvest time.

A more frequent reloading of empty vehicles would mitigate the need for additional vehicle purchases, freeing rural logistics companies to spend their limited capital on soft infrastructure improvements such as IT system enhancements or capacity building.

\section{v. Optimize the Design of Rural Logistics Centers}

The existing transport and logistics networks need to be rationalized to facilitate the movement of multiple types of cargo via multiple transport modes. For example, the bottoms of passenger buses should be used to ship small packages, and crowdsourcing techniques should be used to deploy registered villagers to pick up or deliver packages for other villagers.

With innovative designs, highly functional logistics terminals could be constructed at moderate cost, and would contribute substantially to the efficiency of the rural logistics system. They would eliminate a lot of repetitive effort and would accelerate the implementation of much-needed rural logistics development projects.

\section{vi. Create a Network of Rural Logistics Terminals}

The government should support private sector development of low-cost rural logistics terminals to consolidate shipments of agricultural products brought in by farmers, and to distribute consumer goods and nonlocally produced food to the villagers. These rural logistics centers could serve as nodes connecting village-level roads to county-level and regional roads. They could also facilitate the aggregation of farm products into batches large enough to transport cost-effectively. 


\section{REFERENCES}

Ali Research Institute. 2014. Research Report on Chinese New Farmers (2014). Beijing.

Ali Research Institute. 2016. Research Report on Chinese Taobao Villages (2016). Beijing.

"Beijing Xinfadi Vegetable Wholesale Market: A Tender Fee RMB 3 Million Required for a Stall." Focus on Business Environment, series by CCTV-2. 10 December 2013.

Central Committee of the Communist Party of China. 2004-2017. No. 1 Central Document. Beijing.

Cha, Yingxin et al. 2013. Report on China's Rural Logistics Development. China Cooperative Times.

China International Electronic Commerce Center Research Institute. 2016. China Rural E-Commerce Development Report (2015-2016). Beijing.

China Internet Network Information Center. 2016. Statistical Report on Internet Development in China. Beijing.

Din, Junfa. 2010. The Value Orientation of the Cold Chain Logistics of Agricultural Products. China Business \& Market.

Government of the People's Republic of China, Institute of Food Safety Control and Inspection. 2014. Report on China's E-Commerce in Agricultural Products, 2014-2015. Beijing.

Government of the People's Republic of China, Ministry of Commerce. 2017. Online Shopping Continues to Boom in Rural China. Beijing.

Government of the People's Republic of China, Ministry of Transport; Ministry of Agriculture; State Post Bureau; and China Co-op. 2014. Several Opinions on Promoting the Healthy Development of Rural Logistics Cooperatively to Better Serve Agricultural Modernization. Beijing.

Government of the People's Republic of China, State Council. 2010. Plan on the Development of Cold Chain Logistics for Agricultural Products. Beijing.

Guo, Zuoyu. 2014. Report on the Progress of Investigation and Research on Agricultural Products E-Commerce. Beijing: Ministry of Agriculture.

Huang, Zuhui. 2014. Issues in the Management of Supply Chain for Fresh Agricultural Products in China. Hangzhou: Zhejiang University of Science and Technology. 
Huaxi City Daily. 2015. JingDong Help Service Shop Made Initial Success Four Months After its Establishment-Villagers Praise It for Solving the Last-Mile Problem of Online Shopping. 3 March.

International Business Daily. 2015. Who Is Eating the Profits of Vegetable Producers? 3 May.

Li, Fengrong. 2014. An Empirical Analysis of Supermarket Implementing "Farm to Supermarket Linkage" in the Case of Wumart Group. Beijing: Graduate School of Chinese Academy of Social Sciences.

Liu, Jiangpeng. 2011. Research on the Upgrading Path of the Mode of Agricultural Logistics Chain. Ecological Economy. 2011 (1). pp. 89-91.

Liu, Wei and Wang Xiaoxia. Study on the Optimization of Agricultural Products' Logistics and Distribution in Beijing City from the Perspective of Production and Sales. Beijing: Beijing Jiaotong University.

Long, Wenjun and Wang Huimin. 2014. Observation and Discussion on the Circulation Modes of Fresh Vegetables in China-Based on an Investigation in Shandong, Hainan, and Beijing. Rural Economic Research.

Su, Tai. 2014. "Analysis of Benefits of Planting Tomatoes in Shandong Province." Master's thesis, Shandong Agricultural University.

Twenty First Century Economic Research Institute/ JingDong. 2016. Report on the Rural E-Commerce Consumer Trends 2016. Beijing.

Government of the United States, United States Department of Agriculture, Foreign Agricultural Service. 2009. China - People's Republic of: Annual Report; Tomatoes and Products. Global Agricultural Information Network CH9047. Washington, DC.

Wang, Yuhui and Wen Jinyi. 2015. The Efficiency of Agricultural Products Logistics and its Regional Difference in China. Contemporary Economy \& Management.

Wang, Zhuoqiong. 2013. PostMart Model Means Better Days on the Horizon. China Daily. 12 March (updated).

Wu, Liang 2017. Exploration of New Solutions to Rural E-Commerce from Prospects and Problems. Journal of Jiangxi University of Technology. 2017 (1).

Yang, Hongbao. 2009. Discussion on Improving the Circulation Efficiency of Fresh Agricultural Products-A Revelation from "Buji Mode" in Shenzhen. Logistics Technology.

Yang, Zhihong and Yinli Zhai. 2011. Analysis of the Circulation Cost of Agricultural Product Supply Chain in Supermarket: Proof from Shenyang Vegetable Market. Issues in Agricultural Economy. 2011 (2). 


\section{Promoting Logistics Development in Rural Areas}

Logistics plays an important role in agricultural production and supply-chain management, ultimately enhancing food safety and quality. Improvements in rural logistics help farmers to harvest and market crops more efficiently; and by facilitating communication, they serve to expand the markets for agricultural products. While recognizing the rapidly changing rural landscape in the People's Republic of China, the distribution of goods is still impeded, and the quality of services poor. This study is part of the Asian Development Bank's initiative to support and promote the development of the agriculture sector and establish efficient rural-urban synergies. Read how the private and public sectors can improve and promote logistics development in rural areas.

\section{About the Asian Development Bank}

ADB's vision is an Asia and Pacific region free of poverty. Its mission is to help its developing member countries reduce poverty and improve the quality of life of their people. Despite the region's many successes, it remains home to a large share of the world's poor. ADB is committed to reducing poverty through inclusive economic growth, environmentally sustainable growth, and regional integration.

Based in Manila, ADB is owned by 67 members, including 48 from the region. Its main instruments for helping its developing member countries are policy dialogue, loans, equity investments, guarantees, grants, and technical assistance. 